NBER WORKING PAPER SERIES

\title{
DEFINING CLUSTERS OF RELATED INDUSTRIES
}

\author{
Mercedes Delgado \\ Michael E. Porter \\ Scott Stern \\ Working Paper 20375 \\ http://www.nber.org/papers/w20375
NATIONAL BUREAU OF ECONOMIC RESEARCH
1050 Massachusetts Avenue
Cambridge, MA 02138 \\ August 2014
}

This project has been funded by a grant from the Economic Development Administration of the U.S. Department of Commerce. We received financial support from Harvard Business School. We thank Bill Simpson, Xiang Ao, Rich Bryden, and Sam Zyontz for their invaluable assistance with the analysis. We also acknowledge the insightful comments of two anonymous reviewers, Harald Bathelt, Ed Feser, Frank Neffke, Juan Alcacer, Bill Kerr, Fiona Murray, Christian Ketels, James Delaney, Brandon Stewart, Muhammed Yildirim, Ram Mudambi, Sergiy Protsiv, Jorge Guzman, Sarah Jane Maxted and the participants in the Industry Studies Association Conference, NBER Productivity Seminar, Temple University Seminar, and the Symposium on the Use of Innovative Datasets for Regional Economic Research at George Washington University. The views expressed herein are those of the authors and do not necessarily reflect the views of the National Bureau of Economic Research.

At least one co-author has disclosed a financial relationship of potential relevance for this research. Further information is available online at http://www.nber.org/papers/w20375.ack

NBER working papers are circulated for discussion and comment purposes. They have not been peerreviewed or been subject to the review by the NBER Board of Directors that accompanies official NBER publications.

(C) 2014 by Mercedes Delgado, Michael E. Porter, and Scott Stern. All rights reserved. Short sections of text, not to exceed two paragraphs, may be quoted without explicit permission provided that full credit, including $\odot$ notice, is given to the source. 
Defining Clusters of Related Industries

Mercedes Delgado, Michael E. Porter, and Scott Stern

NBER Working Paper No. 20375

August 2014

JEL No. R0,R1

\begin{abstract}
$\underline{\text { ABSTRACT }}$
Clusters are geographic concentrations of industries related by knowledge, skills, inputs, demand, and/or other linkages. A growing body of empirical literature has shown the positive impact of clusters on regional and industry performance, including job creation, patenting, and new business formation. There is an increasing need for cluster-based data to support research, facilitate comparisons of clusters across regions, and support policymakers and practitioners in defining regional strategies. This paper develops a novel clustering algorithm that systematically generates and assesses sets of cluster definitions (i.e., groups of closely related industries). We implement the algorithm using 2009 data for U.S. industries (6-digit NAICS), and propose a new set of benchmark cluster definitions that incorporates measures of inter-industry linkages based on co-location patterns, input-output links, and similarities in labor occupations. We also illustrate the algorithm's ability to compare alternative sets of cluster definitions by evaluating our new set against existing sets in the literature. We find that our proposed set outperforms other methods in capturing a wide range of inter-industry linkages, including grouping industries within the same 3-digit NAICS.
\end{abstract}

Mercedes Delgado

Temple University and ISC

Fox School of Business

Alter Hall 542

1801 Liacouras Walk

Philadelphia, PA 19122

mdelgado@temple.edu

Michael E. Porter

Harvard University

Institute for Strategy and Competitiveness

Ludcke House

Harvard Business School

Soldiers Field Road

Boston, MA 02163

mporter@hbs.edu
Scott Stern

MIT Sloan School of Management

100 Main Street, E62-476

Cambridge, MA 02142

and NBER

sstern@mit.edu 


\section{Introduction}

There is an increasing need for useful data tools to measure the cluster composition of regions, and support regional policy development as well as business strategy. The goal of this paper is to address this need by providing a rigorous methodology for generating and assessing sets of cluster definitions - groups of industries closely related by skill, technology, supply, demand, and/or other linkages. Our approach is novel by comparing the quality of alternative sets of cluster definitions and also by capturing multiple types of inter-industry linkages. We implement this clustering algorithm to create a new set of U.S. Benchmark Cluster Definitions (BCD), capturing a broad range of inter-industry linkages.

Clusters are geographic concentrations of related industries and associated institutions. The agglomeration of related economic activity is a central feature of economic geography (Marshall, 1920; Porter, 1990; Krugman, 1991; Ellison and Glaeser, 1997). Marshall (1920) highlighted three distinct drivers of agglomeration: input-output linkages, labor market pooling, and knowledge spillovers, which are associated with cost or productivity advantages to firms. Over time, an extensive literature has broadened the set of agglomeration drivers, including local demand conditions, specialized institutions, the organizational structure of regional business, and social networks (Porter, 1990, 1998; Saxenian, 1994; Storper, 1995; Markusen, 1996; Sorenson and Audia, 2000; among others). Thus, clusters contain a mix of industries related by various linkages (knowledge, skills, inputs, demand, and others) and supportive institutions.

The bulk of the cluster literature has been based on detailed case studies (Marshall, 1920; Porter, 1990, 1998; Swann, 1992; Saxenian, 1994). Over time, attention has begun to shift to larger-scale, quantitative studies across regions and industries (Porter, 2003; Feser, 2005). Using particular cluster definitions, studies have shown that the presence of related economic activity matters for regional and industry performance, including job creation, patenting, and new business formation (see among others, Feldman and Audretsch, 1999; Porter, 2003; Feser, Renski, and Goldstein, 2008; Glaeser and Kerr, 2009; Delgado, Porter, and Stern, 2010, 2014; Neffke, Henning, and Boschma, 2011). ${ }^{1}$ This evidence has informed key questions of both research and policy interest: the size of cluster effects, which mechanisms are most important in driving agglomeration, and how clusters diversify and grow in a region. Based on different

\footnotetext{
${ }^{1}$ See Rosenthal and Strange (2004) and Cortright (2006) for a review of economies of agglomeration studies.
} 
definitions of clusters, covering different portions of the economy ranging from high technological intensity industries to manufacturing to all industries defined in the industrial classification system, existing research has generated a range of results on these issues. However, the lack of a comprehensive methodology, and a way to compare alternative sets of cluster definitions, makes it difficult to reconcile key findings. This paper addresses this issue by developing a novel clustering algorithm to generate, assess and compare alternative sets of cluster definitions.

Cluster definitions are groups of industries related by skill, technology, supply, demand, and/or other linkages. This paper focuses on regionally comparable cluster definitions (i.e., the industries that constitute a cluster (e.g., Biopharmaceuticals) are the same for all regions). Interindustry linkages are identified through the co-location patterns of industries across regions, or with a range of national data available across industries. The identified linkages are used to group industries into a set of defined clusters, allowing clusters to be compared across regions.

To generate a set of cluster definitions, we use clustering analysis - numerical methods for the classification of similar objects into groups (Everitt et al., 2011; Grimmer and King, 2011). Our algorithm generates many different cluster configurations, $C$ s, through a clustering function that utilizes a particular measure of the relatedness between any two industries and wellspecified parameter choices (e.g., the number of groups). Each configuration is composed of mutually exclusive groups of related industries (i.e., clusters). The algorithm then provides scores that assess the quality of each $C$ (i.e., its ability to capture meaningful inter-industry linkages within clusters). This allows us to identify the configuration, $C^{*}$, that best captures certain types of inter-industry links. Because an algorithm cannot perfectly substitute for expert judgment, the methodology concludes with an expert assessment and adjustment of individual clusters in $C^{*}$ to determine a final set of cluster definitions, $C^{* *}$.

Our paper contributes to the literature on clusters and economies of agglomeration in several ways. First, the clustering algorithm allows us to compare the quality of alternative sets of clusters using a common approach that generates objective scores (i.e., most clustering methods do not provide scores to help compare across groupings (Everitt et al., 2011; Grimmer and King, 2011)). We can assess cluster configurations that are generated using different interindustry linkage measures. For example, we can evaluate $C$ s generated using pairwise industry co-location patterns to those based on input-output or other measures. We can also compare 
existing sets of cluster definitions. The ability to score sets of clusters can help identify the appropriate sets for addressing particular research and policy questions.

Our scoring approach utilizes a basic clustering principle: creating groupings so that industries within a cluster are more related to each other than to industries in other clusters based on various measures of inter-industry linkages. The score for a given $C$ depends on how well it captures various types of industry linkages. However, what constitutes a useful set of cluster definitions may change depending on the particular research and policy question. Some studies may be interested in a particular type of industry link (e.g., labor occupational links), making sets of cluster definitions that perform better in that link more useful.

Second, our algorithm allows for experimentation with multiple inter-industry linkage measures used in the economies of agglomeration literature, including input-output linkages, occupational linkages, the co-location patterns of industries, and combinations among them. We can then examine the cluster configurations generated based on these different measures. The methodology can incorporate additional inter-industry linkage measures as they become available (e.g., a measure that specifically captures knowledge linkages), and score their resulting cluster sets.

Third, although generating cluster definitions will require expert judgment for some individual clusters, our algorithm is transparent. In the last stage of the algorithm, there is room for expert judgment to correct for inevitable anomalies that arise due to data imperfections and industry definitions. For example, in a given $C^{*}$, there could be industry outliers that do not seem to belong to their assigned cluster. These can be reallocated to their "next best" cluster using a score that assesses the relatedness of the particular industry with another cluster, using a transparent process. Users can assess how adjustments (re-allocations of industries, combining or dividing clusters) impact cluster scores.

Another important contribution of this paper is that we implement our method to generate a new set of benchmark cluster definitions for the U.S. (BCD or $C^{* *}$ ), which captures a wide array of inter-industry linkages. The U.S.-based empirical analysis focuses on grouping 778 6digit NAICS industries in manufacturing and services in 2009, and uses County Business Patterns (CBP), the Benchmark Input-Output Account of the United States, and Occupational Employment Statistics (OES) datasets to define multiple industry relatedness measures. 
The proposed $\mathrm{BCD}$ is generated using inter-industry measures of co-location patterns of employment and the number of establishments, input-output links, and labor occupation links, and contains 51 clusters. We examine the relative performance of the $\mathrm{BCD}$ and three existing sets of (mutually exclusive) cluster definitions: industries within the same 3-digit NAICS, Porter (2003), and Feser (2005). Grouping industries within the same 3-digit NAICS scores poorly in capturing multiple inter-industry linkages, which is perhaps not surprising since the industrial classification system groups industries based on the similarities of their products/services, not on their inter-industry complementarities. Moreover, manufacturing and service industries belong to different parts of the NAICS, so that products and services are definitionally unrelated. Numerous empirical studies on economies of agglomeration have relied solely on industry codes to define inter-industry relatedness, potentially limiting their ability to capture a broad array of relevant industry linkages.

Our benchmark set scores higher in capturing a broader range of inter-industry linkages than the three other prominent sets of cluster definitions. The BCD also scores better or the same as the other sets in input-output linkages and shared labor occupations.

While the analysis is based on U.S. data, our clustering methodology can be implemented in other large and integrated economies with sufficient data availability. At present, however, U.S. data offers several advantages. Comparably large and diversified economic areas like the EU have heterogeneous data accessibility across countries, and current and past barriers to trade across locations can limit economies of agglomeration. Smaller economies (like the Nordics) have access to rich data, but their relative small size leads to specialization in a narrow range of industries.

Our benchmark cluster definitions offer a useful tool for research and policy on regional economic development. They allow the comparison of clusters across locations and over time by mapping the defined clusters into regional units and measuring the specialization patterns of regions in the clusters. Using the BCD, the U.S. Cluster Mapping Project has created a detailed regional cluster dataset that facilitates comparisons across regions and across clusters on numerous dimensions. ${ }^{2}$ For example, the Boston, MA and San Diego, CA Economic Areas have high employment specialization in Biopharmaceuticals, but the size and breadth of the cluster is

\footnotetext{
${ }^{2}$ The U.S. Cluster Mapping website (http://clustermapping.us/) is supported by the U.S. Economic Development Administration, U.S. Department of Commerce.
} 
lower in San Diego, which lacks specialization in biological products (except in-vitro diagnostic substances). The Project also includes data on the business environment and cluster institutions to inform research and policy. This data tool can be used in combination with cluster methods that focus on examining region-specific links among firms, individuals, and supportive institutions in clusters to shed light on the mechanisms at play in particular regional clusters.

The rest of the paper is organized as follows: Section 2 reviews the literature on industry cluster definitions. Section 3 describes our clustering algorithm. In Section 4, we discuss our main findings regarding the generation and assessment of cluster configurations, and Section 5 proposes a set of benchmark cluster definitions. In Section 6 we compare the BCD to existing sets of cluster definitions in the literature, and discuss some research and policy applications. Section 7 concludes.

\section{Defining Industry Clusters}

There are various types of economies of agglomeration identified in the literature, including input-output linkages, labor market pooling, knowledge spillovers, sophisticated local demand, specialized institutions, and the organizational structure of business and social networks (Marshall, 1920; Porter, 1990, 1998; Swann, 1992; Saxenian, 1994; Storper, 1995; Markusen, 1996; among others). These economies of agglomeration manifest themselves in clusters geographic concentrations of related industries and associated institutions. Within regional clusters, firms and associated institutions (i.e., trade organizations, universities, and local government) can operate more efficiently and innovate faster due to sharing common technologies, infrastructure, pools of knowledge and skills, inputs, and responding to demanding local customers.

To implement cluster research and policy, however, we need to measure the boundaries of clusters: What set of related economic activity and institutions constitutes a cluster? Two main approaches to defining clusters have developed over the last 20 years: clusters based on interindustry linkages inferred from multi-region analysis (which we refer to as comparable cluster definitions) and cluster definitions based on observed linkages among industries or firms in a single region (which we refer to as region-specific cluster definitions). Many empirically derived cluster definitions have been generated by researchers and practitioners over the years based on both approaches (see Cortright (2006) and Feser et al., (2009) for a review). The goal of this 
paper is to develop a novel methodology to generate and assess sets of comparable cluster definitions. We next explain both approaches to define clusters and the contribution of our clustering method to the literature.

\subsection{Comparable Cluster Definitions}

A set of comparable cluster definitions allocates individual industries to specific clusters (e.g., Biopharmaceuticals), allowing clusters to be compared across locations. The defined clusters are mapped into regional units to measure the cluster specialization of regions. We can then compare particular clusters across regions, as well as the overall cluster composition of regions. Regional cluster strength reflects specialization in an array of related industries, not specialization in a narrowly defined single industry (Porter, 1998, 2003; Feldman and Audretsch, 1999; Delgado et al., 2014). Thus, regional cluster strength is conceptually similar to the notion of "related variety" introduced by Frenken et al. (2007). For example, a regional cluster with a high breadth of industries will capture related variety.

There are two types of inter-industry relatedness measures that have been developed in the literature (see Section 3.1 for a detailed explanation). Some studies use national-level data to capture particular inter-industry linkages, including knowledge links based on co-patenting (see e.g., Scherer, 1982; Koo, 2005a; Glaeser and Kerr, 2009); input and output links (see e.g., Feser and Bergman, 2000; Feser, 2005); skill links (see e.g., Koo, 2005b; Glaeser and Kerr, 2009; Neffke and Henning, 2013); and product similarity as defined by the industry classification system (e.g., same 3-digit NAICS). Still other studies define measures based on the co-location patterns of industries across many regions to capture various types of linkages (Ellison and Glaeser, 1997; Porter, 2003; Ellison et al., 2010). Only a few studies use the inter-industry relatedness measures to then define clusters of related industries. We next discuss the main existing sets of cluster definitions.

Knowledge Clusters. Studies of knowledge clusters focus on a selected set of U.S. manufacturing industries with high technological intensity. For example, Feldman and Audretsch (1999) group industries that have a common science and technological base, using the Yale Survey of R\&D Managers. This survey assesses the relevance of key academic disciplines for a product category. Industries with similar rankings of the importance of different academic disciplines are grouped into six mutually exclusive clusters. Alternatively, Koo (2005b) groups 
manufacturing industries into seven mutually exclusive knowledge-based clusters using principal component factor analysis on an inter-industry patent-citation flow matrix.

Input-Output Clusters. Feser and Bergman (2000) define a set of U.S. manufacturing clusters using input-output links based on the Benchmark Input-Output Accounts of the United States. They group input-output classification codes (IO codes) into 23 clusters using principal component factor analysis on an inter-industry input-output link matrix. The factor analysis method tends to create highly uneven clusters, with a large number of IO codes grouped into a few clusters. To address this issue, Feser (2005) develops a new methodology based on hierarchical clustering on an input-output link matrix for manufacturing and service activities. This transparent method creates a set of 45 mutually exclusive clusters. Overlapping clusters are then created in a second stage by identifying secondary IO codes highly related to the primary codes within a cluster. For each cluster, the method provides scores of the fit of each IO code within its cluster. The IO codes are then matched to 2002 NAICS codes to create a final set of clusters of related industries.

Co-Location-Based Clusters. Porter (2003) examines the co-location patterns of narrowly defined industries in both service and manufacturing to define clusters, following the principle that co-location reveals the presence of linkages across industries. The methodology first distinguishes traded and local industries. Local industries are those that serve primarily the local markets (e.g., retail), whose employment is evenly distributed across regions in proportion to regional population. Traded industries are those that are more geographically concentrated and produce goods and services that are sold across regions and countries. The set of traded industries excludes natural-resource-based industries, whose location is tied to local resource availability (e.g., mining).

To measure the relatedness between a pair of traded industries (4-digit SIC), Porter (2003) computes the pairwise correlation of industry employment across states using 1996 data. This measure of co-location patterns is referred to as the "locational correlation" of employment (LC-Employment) and could capture various types of inter-industry linkages. Porter (2003) uses an iterative approach to define clusters rather than a clustering function approach. A set of 41 narrow (mutually exclusive) clusters are created using an iterative process to identify pairs and then groups of industries highly linked based on statistically significant locational correlations. In a second stage, a set of broad (overlapping) clusters is created by including other industries 
that have a high locational correlation with the core industries within the narrow cluster. While the cluster definitions are mainly based on the empirical patterns of employment co-location among industries, the Benchmark Input-Output Account of the United States and industry definitions are used to correct the placement of industries with high co-location but low economic relatedness. These cluster definitions have proven very useful in the empirical analysis of the role of clusters on regional performance (see e.g., Porter, 2003; Delgado, Porter, and Stern, 2010, 2014).

\subsection{Region-Specific Cluster Definitions}

Comparable cluster definitions can capture most economic activities and are necessary for studies that aim to examine clusters across regions. However, one limitation of any multiregion cluster approach is that it may overlook specific inter-industry linkages that may exist in particular regional clusters. These idiosyncratic regional linkages are the focus of the regionspecific cluster definitions. This approach focuses on a single region to measure industry and/or firm interdependencies and define the region's clusters. Such studies vary in their industry coverage, types of economic units (industry, technology classes, or firms), types of regional units (administrative or non-administrative), and methods.

A small set of papers defines region-specific clusters for a large set of economic activities. Some of these studies identify specific "driver" industries in which a region has a competitive advantage. Then they use region-specific inter-industry linkages, such as regional input-output models, to define the clusters around the driver industries (Hill and Brennan, 2000). Other studies focus on identifying the (non-administrative) geographic boundaries of a given cluster. To do so, they examine the spatial density of businesses for particular industries (Duranton and Overman, 2005) or the spatial density of patents for particular technology classes (e.g., Kerr and Kominers, 2010; Alcacer and Zhao, 2013). The goal is to identify locations with a high density of economic activity in a particular field that will facilitate inter-firm connections and externalities.

The bulk of region-specific cluster definitions are qualitative and based on case studies that tend to focus on particular clusters (see e.g., Bresnahan and Gambardella (2004); Cortright, 2010; Porter and Ramirez-Vallejo, 2013), for example, the Athletic and Outdoor cluster in Portland (Cortright, 2010). These studies rely on existing cluster organizations, industry 
directories, and other primary data collection to identify clusters. They offer rich details on the firms and institutions within particular defined clusters, but may be less appropriate for comparing clusters across regions.

The conceptual limitation to region-specific approaches to define clusters is that such definitions are based on observed linkages among existing economic activities in a region (Bathelt, Malmberg, and Maskell, 2004; Maskell and Malmberg, 2007; Feser et al., 2009; Bathelt and $\mathrm{Li}, 2013$ ). Activities that are not present in a region (e.g., industries, technology classes, and labor occupations that are not present) are classified as unrelated to the other activities in the region. However, such non-present activities could be related to the activities in the region, but historical factors, market imperfections or other factors may have prevented their development. Region-specific cluster definitions could thus be too narrow (or myopic) in terms of the linkages captured because they abstract from the linkages that may be present in other locations. Thus, region-specific cluster definitions could be complemented by comparable cluster definitions derived from patterns across multiple regions.

This paper creates a new cluster methodology that systematically generates comparable cluster definitions based on multiple types of inter-industry linkages. This approach provides scores that assess the ability of each set of definitions to capture high inter-industry linkages within individual clusters. For example, we can compare the Feser (2005) and Porter (2003) sets of cluster definitions as well as other sets.

We implement the algorithm and propose a new set of U.S. Benchmark Cluster Definitions (BCD) that captures a wide variety of inter-industry linkages. This set can be updated over time as new data (e.g., new industry definitions) becomes available.

\section{The Clustering Algorithm}

In order to derive clusters of industries, we use cluster analysis, or numerical methods to classify similar objects (cities, people, genes, industries, etc.) into groups (Everitt et al., 2011). In contrast to network analysis, where each object is related to any other object, ${ }^{3}$ cluster analysis

\footnotetext{
${ }^{3}$ For example, some papers focus on defining the "product space" - the network of relatedness between products. Hidalgo et al. (2007) define the product space for exported goods. Other studies focus on specific dimensions of the product space, such as the technology, knowledge, or market space (Jaffe, Trajtenberg, and Henderson, 1993; Neffke et al., 2011; Bloom et al., 2012).
} 
creates groups (termed clusters) in such a way that objects in the same cluster are more similar among themselves than to those in other clusters.

Defining clusters of related industries involves a number of key choices that can be parameterized in a clustering algorithm. The algorithm includes criteria for scoring alternative cluster configurations. Once the most promising configuration is identified, the algorithm addresses outlier industries to develop a final set of cluster definitions.

The clustering algorithm is designed to define mutually exclusive clusters, where each industry is uniquely assigned to one cluster. The methodology also allows the measurement of relatedness between any pair of (mutually exclusive) clusters and the creation of overlapping clusters (with individual industries shared by multiple clusters).

Drawing on Porter (2003), our method first distinguishes between traded industries (geographically concentrated) and local industries (geographically dispersed). There are 1,088 6digit NAICS-2007 industries in the 2009 CBP data (excluding farming and some government activity). We identify 778 traded industries using the specialization and concentration patterns of each industry across U.S. regions. In 2009, the traded industries account for $36 \%$ of total U.S. employment, $50.5 \%$ of payroll, and more than $90 \%$ of patenting activity. ${ }^{4}$

The analysis focuses on grouping the 778 traded industries in service and manufacturing into non-overlapping groups. We refer to each cluster configuration as $C$ and its individual clusters as $c$. There are five inter-related steps to create and assess each configuration $C$ : (1) define a similarity matrix $M_{i j}$ that captures the relatedness between any two industries; (2) make broad parameter choices $\beta$; (3) use a clustering function to create a configuration $C$ based on the similarity matrix and parameter choices $\left(C=F\left(M_{i j}, \beta\right)\right)$; (4) calculate performance scores for each $C$ and identify the most promising configuration $C^{*}$; and (5) assess and correct the individual clusters in $C^{*}$ to determine the finalized set of cluster definitions $C^{* *}$. Each of these clustering algorithm steps is explained in detail below. ${ }^{5}$

\subsection{Step 1: Similarity Matrix}

The first step to group related industries into clusters is to define the degree to which each pair of industries is related. A similarity matrix $M_{i j}$ provides the relatedness between any pair of

\footnotetext{
${ }^{4}$ The complete description of the traded and local categorization can be found on the U.S. Cluster Mapping website. ${ }^{5}$ All the steps of the algorithm were implemented using STATA software.
} 
industries $i$ and $j$. The matrix is based on the choice of indicator and the similarity measure. Indicators used in the literature include employment, number of establishments, measures of buyer-supplier linkages, and measures of shared labor requirements. The choice of a similarity measure allows the user to decide how the distance between two industries $i$ and $j$ should be measured (e.g., correlation coefficient, Euclidean, Jaccard index, or user-defined measures).

There are many alternative similarity matrices. Our analysis focuses on the inter-industry relatedness measures most frequently used in the field of regional studies to capture economies of agglomeration. The similarity matrices can be divided into three types. First, there are $M_{i j}$ that exploit co-location patterns across many regions to capture various types of inter-industry linkages. This group includes the locational correlation of employment developed by Porter (2003) and the Ellison and Glaeser (1997) coagglomeration index. Second, there are $M_{i j}$ that focus on national-level inter-industry linkages, including measures based on national input and output tables (see Feser and Bergman, 2000; Feser, 2005; Ellison, Glaeser, and Kerr, 2010) and on labor occupation links (Glaeser and Kerr, 2009). Third, we create multidimensional matrices that use a combination of these matrices. In what follows, we explain each of these similarity matrices as well as additional industry linkages we do not directly measure.

Pairwise Industry Co-location Patterns. Before we explain the co-location similarity matrices used in our analysis, we need to clarify the regional unit used for these measures and the source of the underlying data. There are two spatial approaches to measure the co-location patterns of industries across regions: using discrete spatial units like states (Ellison and Glaeser, 1997; Porter, 2003; Ellison, Glaeser, and Kerr, 2010) and using continuous spatial units that are based on the density of businesses (Duranton and Overman, 2005). Discrete spatial units that capture relevant regional markets offer a reasonable starting point for understanding co-location patterns. The differences between discrete and continuous co-location measures in their ability to capture inter-industry externalities can be tested. For example, Ellison, Glaeser, and Kerr (2010) show that their co-agglomeration index based on states and an approximation of the continuous co-agglomeration metric developed by Duranton and Overman (2005) both capture similar interindustry Marshallian effects (input-output, skill, and knowledge links). Using continuous spatial measures is beyond the scope of this paper due to data limitations.

We use meaningful administrative regional units: Economic Areas (EAs) as defined by the Bureau of Economic Analysis (BEA). EAs represent 179 relevant regional markets that cover 
the entirety of the continental United States (Johnson and Kort, 2004). The underlying employment and count of establishments of an EA-industry is sourced from the County Business Patterns (CBP) 2009 data. $^{6}$

Locational Correlation (LC). Porter (2003) examines the employment co-location patterns of pairs of industries to capture inter-industry linkages of various types (e.g., technology, skills, supply, or demand links). He defines the locational correlation of employment (LC-Employment) of a pair of industries as the correlation coefficient between employment in industry $i$ and employment in industry $j$ in a region $r$ :

$$
\text { LC-Employment }_{i j}=\text { Correlation }_{\left(\text {Employment }_{i r}, \text { Employment }_{j r}\right)} \text { ) }
$$

Similarly, we also define an alternative locational correlation based on the count of establishments in a region-industry:

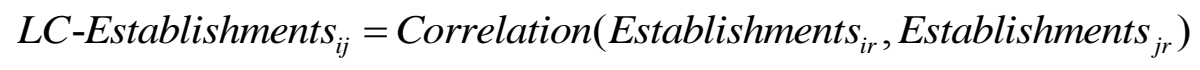

Economies of agglomeration channels include firms as well as employees. The presence of numerous establishments can facilitate inter-firm interactions that result in spillovers (Glaeser and Kerr, 2009). Thus, the co-location patterns of count of establishments could help capture inter-industry linkages that are facilitated by the number of businesses.

The correlation coefficient is a well-known distance measure for continuous data used in clustering analysis (Everitt et al., 2011). The LC measures can be implemented for very granular industry definitions, and its scale is easy to interpret, with values between -1 and 1 . Positive and large values suggest that there are relevant economic interdependencies between a pair of industries. For example, if the location of employment (count of establishments) in electronic computers and software is highly correlated, it would suggest that both industries are linked. While the $L C$ measures tend to capture relevant linkages, it is possible that in some cases industries with high co-location may have little economic relatedness but instead capture shared natural resources. As we discuss further below, this does not limit the usefulness of co-location measures.

$L C$ also could be sensitive to the size of the regions (Porter, 2003). For example, for pairs of industries with employment concentrated in large regions (i.e., with many pairs of zero

\footnotetext{
${ }^{6}$ The CBP data is made available at the county, state, and U.S. level. Economic Area data is built up from the county file. CBP data uses cell suppression in certain geography-industries with a small presence of firms. When employment data is suppressed, a range is reported. We utilize the midpoint in the range in our data.
} 
activity across regions), the $L C$ could be biased. We limit this problem by using EAs versus using smaller regional units (like counties) that do not fully capture the regional market. We also implement several sensitivities to EA size that suggest this problem is limited. ${ }^{7}$ In our data, the average LC-Employment and LC-Establishments of a pair of industries are 0.30 and 0.52 , respectively (Table 2).

The Coagglomeration Index (COI). This index developed by Ellison and Glaeser (1997) captures whether two industries are more co-located than expected if their employment is distributed randomly. We use the revised version of the COI in Ellison, Glaeser, and Kerr (2010):

$$
\mathrm{COI}_{\mathrm{ij}}=\sum_{\mathrm{r}}\left(\mathrm{s}_{\mathrm{ri}}-\mathrm{x}_{\mathrm{r}}\right) *\left(\mathrm{~s}_{\mathrm{rj}}-\mathrm{x}_{\mathrm{r}}\right) /\left(1-\sum_{\mathrm{r}} \mathrm{x}_{\mathrm{r}}^{2}\right)
$$

where $s_{r i}$ is the share of industry $i$ 's employment in region $r$; and $x_{r}$ measures the aggregate size of region $r$, which they model as the mean employment share in the region across industries. A value of zero or negative for $C O I$ would suggest no externalities-driven co-agglomeration. The higher the positive value of the COI, the greater is the potential for externalities between two industries, but it is not easy to assess whether particular positive values are large or small.

Ellison et al. (2010) compute the COI for pairs of manufacturing industries (3-digit SIC codes) and use states as the main regional unit. They find that each of the three Marshallian effects (input-output, skill, and knowledge links) matter for the co-agglomeration of a pair of industries. However, shared natural advantages (e.g., coastal access) also matter for the coagglomeration, but this effect is less important than the cumulative effect of the Marshallian factors. Their findings suggest that co-location captures not only meaningful economic interdependencies and externalities between industries, but also some natural advantages.

We extend the Ellison, Glaeser, and Kerr (2010) analysis, and compute the COI for 6digit NAICS manufacturing and service industries, using EAs as the regional unit. The mean of this variable is around zero with a standard deviation of 0.010; and the values range from a minimum of -0.05 to a maximum of 0.37 (Table 2). These values are very similar to those obtained in Ellison et al. (2010) for 3-digit SIC manufacturing industries and with a state as the regional unit. In our data, the $C O I$ is skewed, with $90 \%$ of the distribution below 0.01 .

\footnotetext{
${ }^{7}$ We compute alternative LC matrices by dropping the 10 smallest and 10 largest EAs, and these LC matrices are highly correlated to our baseline measures based on all EAs.
} 
National-Level Inter-Industry Links. We explain the next two similarity matrices that are based on national-level data: input-output and labor occupation links. Because these measures do not consider location patterns, they may capture industry interdependencies that are not geographically bounded.

Input-Output Links (IO). Measures based on the Benchmark Input-Output Accounts of the United States are widely used to capture supplier and buyer flows between industries (see Feser, 2005; Ellison, Glaeser, and Kerr, 2010; Alcacer and Chung, 2012). Following Ellison et al. (2010), we construct a symmetric $I O$ link between any pair of industries $i, j$ based on the maximum of all unidirectional input and output links:

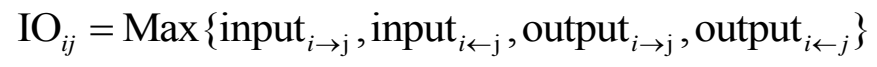

The input $_{i \rightarrow j}$ link is the share of industry $i$ 's total value of inputs that comes from industry $j$, and the output $_{i \rightarrow j}$ link is the share of industry $i$ 's total value of outputs that goes to industry $j{ }^{8}$ The $I O_{i j}$ link takes a minimum value of zero if the two industries do not buy from or sell to each other, and a maximum value of 1 if any of the two industries buy or sell exclusively from or to the other.

To compute this variable, we use the 2002 Benchmark Input-Output Account of the United States developed by the BEA. The average of this variable is 0.02 (Table 2). Most pairwise industrial combinations have a small IO link (also documented at Ellison et al., 2010), making the distribution over all pairwise combinations skewed to the right. In our sample, $90 \%$ of the distribution of this variable is below 0.06. Overall, input-output tables are more detailed for manufacturing than service industries, and so may better capture links among manufacturing industries. ${ }^{9}$

In the sensitivity analysis, we also compute a more conservative $I O$ link score that takes the average (versus maximum) of the unidirectional input and output links, correcting downwards the score for pairs of industries with large asymmetries in their links. The average

\footnotetext{
${ }^{8}$ To properly capture the strength of the input-output links between two industries, we compute these percentages excluding final consumption and value-added commodity codes.

${ }^{9}$ In the underlying input-output data, many manufacturing industries are only available at the $4 / 5$-digit NAICS level, and many service industries at the 2/3-digit NAICS level. The following activities are aggregated at the 2-digit NAICS level: Construction (23 NAICS), Wholesale trade (42 NAICS), Retail trade (44 and 45 NAICS), and Management of Companies and Enterprises (55 NAICS). This higher level of aggregation may induce some measurement error in the links among the corresponding 6-digit NAICS industries (e.g., we have to assume that any 6-digit industries within Wholesale trade have the same input-output links with other 6-digit industries).
} 
and maximum pairwise $I O$ links are highly correlated, and our findings are robust to using these alternative measures. $^{10}$

Labor Occupation Links (Occ). Labor occupations have been used to measure the extent to which industries share similar skills (Koo, 2005a; Glaeser and Kerr, 2009). We use the Occupational Employment Statistics (OES) Survey of the Bureau of Labor Statistics (BLS; 2009 data). The OES data provides 792 non-governmental occupations and information on the prevalence of these occupations for each industry (i.e., for each occupation (e.g., computer programmers); it provides the percentage of that occupation in the total occupational employment of the industry). Using this data and following Glaeser and Kerr (2009), we compute the pairwise correlation between the occupation composition of any two industries:

$$
\text { Occ }_{i j}=\text { Correlation }_{\left(\text {Occupation }_{i}, \text { Occupation }_{j}\right)}
$$

where Occupation $_{i}$ is a vector with the percentage of each of the 792 occupations in the total occupational employment of industry $i$. A limitation of this measure is that occupation data is aggregated at the 4-digit NAICS level (i.e., industries with the same 4-digit NAICS will have the maximum occupational link by construction). ${ }^{11}$ The average labor occupation correlation in our sample is $0.18 .^{12}$

Multidimensional Similarity Matrices. We also create combinations of the unidimensional similarity matrices described above. Creating multidimensional similarity matrices begins with understanding the relationship between the unidimensional matrices. Looking at the correlations in Table 3, LC-Employment is highly correlated with $L C$ Establishments (correlation of 0.77) and with the coagglomeration index (correlation of 0.36). These high correlations are robust to the size of the industry and to manufacturing and service industries. IO links have a modest positive correlation with the other measures. We also explore a matrix that captures product similarity as defined by the industry code (NAICS-3). This matrix is equal to 1 for pairs of industries with the same 3-digit NAICS code (and 0 otherwise), and

\footnotetext{
${ }^{10}$ Other papers use measures of indirect input-output links that capture the extent to which a pair of industries have meaningful suppliers and buyers in common (see Feser, 2005).

${ }^{11}$ We are using 7-digit Standard Occupational Classification (SOC) and 4-digit NAICS data because of better coverage. The data can be accessed at http://www.bls.gov/oes/oes dl.htm.

${ }^{12}$ Another way to measure skill links between industries is to examine the actual flow of employment using matched employer-employee data for the workforce of a country. See Neffke and Henning (2013) inter-industry skillrelatedness analysis for the Swedish economy.
} 
relates very poorly with all similarity matrices except with occupational linkages (correlation of $0.45)$.

By using a multidimensional similarity matrix, we can better capture more types of interindustry links (e.g., demand, supply, skills, knowledge, and others), and we can overcome some of the data limitations of the unidimensional matrices (see Table A1 in the Appendix for the definitions of all $M_{i j}$ used). For example, we compute an $M_{i j}$ that we call $L C-I O-O c c_{i j}$, which is the average of four (standardized) individual matrices: LC-Employment $i j$, LC-Establishments ${ }_{i j}$, $I O_{i j}$, and $O c c_{i j .}{ }^{13}$ The multidimensional $L C-I O-O c c$ has a high and statistically significant correlation with each of the individual matrices (Table 3). This suggests that a pair of highly linked industries based on one particular measure (e.g., IO) will also tend to be meaningfully related based on the multidimensional similarity matrix. Thus, LC-IO-Occ seems to better capture various inter-industry links.

Through our algorithm, we can compare how well cluster configurations derived from different similarity matrices perform given the validation scores developed in Step 4 below. We can then assess which matrices seem to result in cluster configurations that capture the broadest range of inter-industry links (see Section 4).

Similarity Matrices and Alternative Agglomeration Mechanisms. While we explore a particular set of relevant inter-industry measures, there are specific agglomeration mechanisms that we do not measure explicitly, such as knowledge linkages and social linkages.

Prior studies that focus on aggregated industries in manufacturing examine inter-industry knowledge linkages using patent citation patterns (e.g., Koo, 2005b; Ellison, Glaeser, and Kerr, 2010). We cannot create inter-industry patenting linkages due to data limitations. ${ }^{14}$ However, knowledge linkages may be partly captured by our industry linkage measures. For example, colocation patterns of industries could capture some knowledge links as shown by Ellison, Glaeser, and Kerr (2010). Two industries may co-locate across regions because they share knowledge, and proximity facilitates the flow of knowledge. Similarly, if two industries share labor occupations, knowledge linkages could flow more easily.

We also do not measure social linkages of firms and individuals, which are important to define regional clusters. The inter-industry economic links captured by our measures can

\footnotetext{
${ }^{13}$ We standardize the unidimensional matrices since their scale and/or distribution are different (see Table 2).

${ }^{14}$ We use narrowly defined industries (6-digit NAICS), making the bridge to patent classes noisy. Additionally, many service industries have low patent intensity.
} 
facilitate opportunities for inter-firm interactions. For example, firms operating in industries that share labor requirements or other inputs are more likely to interact and develop socioeconomic links.

If measures of inter-industry knowledge linkages or social linkages become available, they could be incorporated into our clustering algorithm. We could compare them against other similarity matrices, and assess how cluster configurations that are generated using the new matrices perform in the validation scores defined in Step 4 below.

More broadly, the nature and intensity of knowledge and socioeconomic linkages can vary significantly across regional clusters. Studies of the network among firms, individuals, and associated institutions will be especially informative as to the mechanisms at work in specific clusters (Sorenson and Audia, 2000; Rosenthal and Strange, 2003; Feldman, Francis, and Bercovitz, 2005; Bathelt, Malmberg, and Maskell, 2004; Storper and Venables, 2004; Lorenzen and Mudambi, 2013).

\subsection{Step 2: Broad Parameter Choices}

The parameter choices $(\beta)$ required as inputs to the clustering functions include setting the initial number of clusters (i.e., number of groups), determining how the underlying data should be normalized, and determining the starting values for the clustering function.

An important parameter choice in clustering analysis is the initial number of clusters (numc). There are 41 clusters in Porter (2003) and 45 input-output based clusters in Feser (2005). Current methods to identify the "optimal" number of clusters in clustering analysis are very inconclusive (Everitt et al., 2011). Therefore, we explore values for the number of clusters between 30 and 60. Overall, too few or too many groups could result in less useful cluster definitions. Too few clusters could result in large clusters that include industries that are not very related; and too many clusters could result in clusters that are not meaningfully different from each other. Using Step 4 in the cluster algorithm (described below), it is possible to compare the quality of different configurations based on differences in the initial number of clusters.

The other two parameter choices refer to the starting values and the type of normalization of the underlying data for the clustering functions. The starting values were chosen at random. The underlying data was either untransformed (raw) or row-standardized (rst). These two parameter choices are relevant only for partition-clustering functions: kmeans and kmedians. The 
normalization of the data can be important for these two clustering functions since it could result in a better centroid for each individual cluster. ${ }^{15}$

\subsection{Step 3: Clustering Function}

Clustering functions are designed to find the greatest relatedness among industries within each cluster. There are several clustering functions $\mathrm{F}(\bullet)$ for grouping industries into clusters (see Everitt et al., 2011; Grimmer and King, 2011). Each function creates a new grouping $C$ based on the similarity matrix and parameter choices: $C=F\left(M_{i j}, \beta\right)$. Our analysis uses the main cluster functions for continuous data: the hierarchical function (with Ward's linkage) and centroidbased clustering functions (kmean and kmedian). ${ }^{16}$

Only hierarchical functions allow the user to import a particular similarity matrix. In contrast, kmean and kmedian functions require the underlying raw data to directly compute the similarity matrix (and centroids). Thus, for similarity matrices that require additional manipulation of the underlying data (e.g., $I O$ or $C O I$ ), we can only use the hierarchical function.

Example of Steps 1 to 3 of the Clustering Algorithm. To illustrate Steps 1 to 3 of our algorithm, we replicate a set of cluster definitions that we already know, namely the 3-digit NAICS groupings. We define the similarity matrix $N A I C S-3_{i j}$ as a symmetric binary matrix where pairs of industries within the same 3-digit NAICS code are assigned a value of 1 (and a value of 0 otherwise). Then, we set the broad parameters $(\beta)$ so that there are 66 clusters just as there are 66 different 3-digit NAICS codes for our 778 industries. Finally, we run the hierarchical clustering function using the NAICS-3 matrix and 66 clusters. As expected, we find that the resulting grouping $C$ is indeed equal to the NAICS-3 groupings, validating the clustering algorithm.

\subsection{Step 4: Performance Scores for Each C}

Given the number of possible similarity matrices, parameters, and clustering functions that could be chosen, the number of alternative cluster configurations is quite large. By combining the choices described above in Steps 1 to 3 in different ways, we have generated 713

\footnotetext{
${ }^{15}$ The centroid of a cluster is the mean industry employment (for kmean) and the median industry employment (for kmedian). These centroids could be biased towards larger regional industries. To limit this problem, we allow for row-standardization of the region-industry employment/establishment data.

${ }^{16}$ We also tried hierarchical clustering with average linkages, but the resulting individual clusters were very uneven. See Grimmer and King (2011) for a new clustering approach that combines multiple clustering functions.
} 
different Cs. For example, choosing the LC-Employment similarity matrix, 40 clusters, raw underlying data, and the kmean clustering function will result in one configuration $C_{l}$. Alternatively, choosing the $I O$ links similarity matrix, 35 clusters, and the hierarchical clustering function will result in a different configuration $C_{2}$ (see Table 1 for examples of $C \mathrm{~s}$ ).

Without some way to evaluate the relative quality of all these $C \mathrm{~s}$, it is very hard to find the most useful sets of definitions that incorporate a broad range of inter-industry linkages. The cluster analysis literature often lacks satisfactory methods for evaluating different categorization schemes (Grimmer and King, 2011). In contrast, our approach provides a score for each configuration $C$. In order to generate these scores, we must first address the question, What makes a good set of cluster definitions?

In our analysis, the primary criterion for a good set of cluster definitions is that industries within a particular cluster (e.g., the Automotive cluster) should be more closely related among themselves than to industries in other clusters. In other words, individual clusters should be meaningfully different from each other, and individual industries should fit well within their own cluster. Our score approach assesses this by using alternative measures of inter-industry linkages that we use for creating validation sub-scores (e.g., sub-scores based on input-output links). Our view is that a useful set of clusters will capture various types of industry linkages, including demand, supply, skills, and others (Marshall, 1920; Porter, 1998). Thus, we develop an overall validation score (VS) for each $C$ that combines sub-scores based on alternative industry measures.

A secondary criterion is that the configurations should be robust. We would prefer cluster definitions that are similar to other well-performing cluster definitions generated by the algorithm, since this would suggest that they are more robust. We develop Overlap Scores (OS) to capture the overlap of each $C$ to other configurations.

Those $C$ s with the highest ranked validation scores are then subject to the robustness criteria to select the better configurations. The configuration that does relatively well in all criteria is the $C^{*}$ selected to undergo further assessment in Step 5. In the remainder of this section, we explain the validation and overlap scores.

Validation Scores. We develop validation scores that capture the extent to which individual clusters and industries have high Within Cluster Relatedness (WCR) relative to Between Cluster Relatedness (BCR) with other clusters. The validation scores assess the quality 
of a cluster configuration $C$ along two dimensions. The first score, VS-Cluster, captures whether individual clusters in $C$ are meaningfully different from each other. The second score, VSIndustry, assesses the fit of individual industries within their own cluster. The two scores are related, but capture different information. For example, in cluster configurations with many clusters, industries could fit very well in a cluster, but the individual clusters may not be very different from each other. Alternatively, in other cluster configurations with a few large clusters, individual clusters may be meaningfully different, but numerous industries may fit better in other clusters.

At the cluster level, we define $\mathrm{WCR}_{\mathrm{c}}$ as the average relatedness between pairs of industries within a cluster, while $\mathrm{BCR}_{\mathrm{c}}$ is the average relatedness between industries in cluster $c$ and those in another cluster. For example, consider two clusters in $C$ : cluster $c_{1}$ with industries $a_{1}, a_{2}$ and cluster $c_{2}$ with industries $b_{1}, b_{2}$; and a similarity matrix $M_{i j}$ (e.g., LC-Employment) that may be different from the one used to generate $C$. Then, the WCR of focal cluster $c_{1}$ is $\mathrm{WCR}_{\mathrm{c}_{1}}=\mathrm{M}_{\mathrm{a}_{1} \mathrm{a}_{2}}$, and the BCR of $c_{1}$ and $c_{2}$ is $\mathrm{BCR} \mathrm{c}_{1}, \mathrm{c}_{2}=\operatorname{Avg}\left(\mathrm{M}_{\mathrm{a}_{1} \mathrm{~b}_{1}}, \mathrm{M}_{\mathrm{a}_{1} \mathrm{~b}_{2}}, \mathrm{M}_{\mathrm{a}_{2} \mathrm{~b}_{1}}, \mathrm{M}_{\mathrm{a}_{2} \mathrm{~b}_{2}}\right)$.

For each focal cluster $c$ in $C$, we compute its BCR with every other cluster and examine the resulting distribution to compute two cut-off values - the average and the 95th percentile values $\left(\mathrm{AvgBCR}_{\mathrm{c}}\right.$ and Pctile95BCR $)$. For example, if there are 47 clusters in $C$, for each focal cluster $c$ we then have 46 different $\mathrm{BCR}_{\mathrm{c}}$ values, and we compute the average and the 95th percentile of the $\mathrm{BCR}_{\mathrm{c}}$ values. We can then assess whether a cluster's $\mathrm{WCR}_{\mathrm{c}}$ is higher than these two threshold values.

Once we define $\mathrm{WCR}_{\mathrm{c}}, \mathrm{AvgBCR}_{\mathrm{c}}$, and Pctile95BCR for each cluster in $C$, we compute a validation score that captures the percent of clusters with high $\mathrm{WCR}_{\mathrm{c}}($ VS-Cluster). This score is made up of two broad sub-scores that we average. The first calculates the percent of clusters in $C$ with $\mathrm{WCR}_{\mathrm{c}}$ higher than $\mathrm{AvgBCR}_{\mathrm{c}}(V S$-Cluster $A v g)$ based on a particular similarity matrix $M_{i j}$. The second sub-score is similar but more restrictive; it calculates the percent of clusters in $C$ with $\mathrm{WCR}_{\mathrm{c}}$ higher than Pctile95BCR $\mathrm{c}_{\mathrm{c}}$ (VS-Cluster Pctile95):

$$
\begin{aligned}
& \text { VS-Cluster Avg } \left.{ }_{\mathrm{C}}^{\mathrm{M}}=\left(100 / \mathrm{N}_{\mathrm{c}}\right)^{*} \sum_{\mathrm{c}} \mathrm{I}_{\mathrm{WCR}}\left(\mathrm{M}_{\mathrm{ij}}\right)>\operatorname{AvgBCR}_{\mathrm{c}}\left(\mathrm{M}_{\mathrm{ij}}\right)\right] \\
& \text { VS-Cluster Pctile95 } \left.{ }_{\mathrm{C}}^{\mathrm{M}}=\left(100 / \mathrm{N}_{\mathrm{c}}\right)^{*} \sum_{\mathrm{c}} \mathrm{I}_{\left[\mathrm{WCR}_{\mathrm{c}}\right.}\left(\mathrm{M}_{\mathrm{ij}}\right)>\operatorname{Pctile} 95 \mathrm{BCR}_{\mathrm{c}}\left(\mathrm{M}_{\mathrm{ij}}\right)\right]
\end{aligned}
$$

where $N_{c}$ is the number of clusters in $C$ and $I$ is an indicator function equal to 1 if for a given cluster $c \mathrm{WCR}_{\mathrm{c}}>\mathrm{AvgBCR}_{\mathrm{c}}$ in (6a) or $\mathrm{WCR}_{\mathrm{c}}>\mathrm{Pctile}$ 5BCR $\mathrm{B}$ in (6b). We then average these two 
sub-scores to compute VS-Cluster ${ }^{\mathrm{M}}$. For example, for $C^{*}$ the VS-Cluster ${ }^{\text {LC-Emp }}$ score is $67.0 \%$, meaning that approximately 31 (of 47) clusters have relatively high $\mathrm{WCR}_{\mathrm{c}}$ based on $L C$ Employment (Table 5).

We compute (6a) and (6b) based on four different $M_{i j}$ (LC-Employment, $L C$ Establishments, $I O$, and $O c c$ ). Note that the similarity matrices we use here are not dependent on the similarity matrix used to create $C$. This allows us to calculate validation scores that can be consistently compared regardless of the underlying measures used to generate $C s$. This results in eight sub-scores that we then average to generate the main validation score. ${ }^{17}$ A score of 100 indicates that all the individual clusters in $C$ contain industries that are highly related based on multiple linkages. For example, for $C^{*}$ the VS-Cluster is $81.6 \%$ (Table 5), while the average of this variable across all $C s$ is $73.9 \%$ (Table 4$)$.

So far, we have computed a validation score that examines individual clusters. We then compute a validation score based on the fit of individual industries within their own cluster (VSIndustry). For a given industry $i$, we want it to be more related to the industries within its own cluster than to industries outside its cluster. ${ }^{18}$ Similar to our calculation of VS-Cluster, we measure the percent of industries with $\mathrm{WCR}_{\mathrm{ic}}$ higher than their average $\mathrm{BCR}_{\mathrm{i}}$ (VS-Industry Avg) and higher than the 95th percentile of $\mathrm{BCR}_{\mathrm{i}}$ (VS-Industry Pctile95) based on various similarity matrices.

$$
\begin{aligned}
& \text { VS-Industry Avg } \left.{ }_{\mathrm{C}}^{\mathrm{M}}=\left(100 / \mathrm{N}_{\mathrm{i}}\right)^{*} \sum_{\mathrm{i}} \mathrm{I}_{\mathrm{WCR}}\left(\mathrm{WC}_{\mathrm{ij}}\right)>\operatorname{AvgBCR}_{\mathrm{i}}\left(\mathrm{M}_{\mathrm{ij}}\right)\right] \\
& \text { VS-Industry Pctile95 } \left.5_{\mathrm{C}}^{\mathrm{M}}=\left(100 / \mathrm{N}_{\mathrm{i}}\right)^{*} \sum_{\mathrm{i}} \mathrm{I}_{\left[\mathrm{WCR}_{\mathrm{ic}}\right.}\left(\mathrm{M}_{\mathrm{ij}}\right)>\operatorname{Pctile} 95 \mathrm{BCR}_{\mathrm{i}}\left(\mathrm{M}_{\mathrm{ij}}\right)\right]
\end{aligned}
$$

where $N_{i}$ is the number of industries in $C$. We compute (7a) and (7b) based on four different $M_{i j}$ (LC-Employment, LC-Establishments, IO, and Occ), resulting in eight sub-scores that we then average to generate the validation score VS-Industry.

The overall validation score $V S$ of a cluster configuration is computed as the average of the VS-Cluster and VS-Industry scores. Those Cs with highly ranked scores for both VS-Cluster

\footnotetext{
${ }^{17} \mathrm{We}$ do not include validation sub-scores based on $C O I$ to compute our main validation scores because $C O I$ and LC-Employment will capture similar industry interdependencies.

${ }^{18}$ The industry $\mathrm{WCR}_{\mathrm{ic}}$ score is the average pairwise relatedness between the focal industry and the other industries within the cluster; while industry BCR is the average relatedness between the focal industry and industries in a different cluster. Using the example above, if we consider focal industry $a_{1}$ in cluster $c_{l}$, then its $\mathrm{WCR}_{\mathrm{a} 1 \mathrm{c}}=\mathrm{M}_{\mathrm{a} 1, \mathrm{a} 2}$ and the $\mathrm{BCR}$ of $a_{1}$ with industries in cluster $c_{2}$ is $\mathrm{BCR}_{\mathrm{a} 1, \mathrm{c} 2}=\operatorname{Avg}\left(\mathrm{M}_{\mathrm{a} 1, \mathrm{~b} 1,}, \mathrm{M}_{\mathrm{a} 1, \mathrm{~b} 2}\right)$.
} 
and VS-Industry are the most promising configurations (the "candidates" $C$ "s). The final candidate $C^{*}$ is the configuration with the maximum $V S$ score. For example, Table 5 illustrates the validation scores and sub-scores for the candidate configuration $C^{*}$.

Overlap Scores. The candidate $C^{*} \mathrm{~s}$ are subject to the robustness criteria. We develop scores that capture the robustness of a particular $C$ by comparing the industry overlap between the clusters in $C$ and the clusters in other candidate configurations. To compare a configuration $C_{1}$ to another $C_{2}$, for each individual cluster $c$ in $C_{1}$, we find a matching cluster $b$ in $C_{2}$ (i.e., the cluster $b$ that has the highest industry overlap with $c$ ). Specifically, we compute the overlap between a pair of clusters $c, b$ using the geometric mean of the industry overlap in each direction:

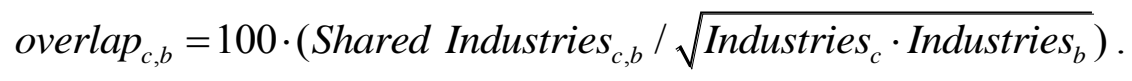

Where Shared Industries is the number of industries in common in $b$ and $c$; and Industries are the number of industries in each cluster. The maximum overlap of a pair of matched clusters is 100. Then we define the overlap score of $C_{1}$ to $C_{2}$ as the average industry overlap across $C_{1}$ 's

clusters: Overlap Score ${\text { C }-C_{2}}_{N_{c}}=\frac{1}{c \in C_{1}}$ overlap $_{c, b}$ Similarly, we compute the average overlap of $C_{1}$ with all other candidate configurations (Overlap Score C-Candidates). For example, on average the proposed candidate $C^{*}$ has an industry overlap of $77.6 \%$ with other relevant candidates, indicating that these alternative $C$ s tend to provide, on average, similar groupings of industries (Table 7).

The configuration that does relatively well in the validation score (and overlap score) is the $C^{*}$ selected to undergo further assessment in Step 5. Generally, the higher the validation scores, the better the $C^{*}$. However, there could be anomalies within individual clusters that would require some assessment and reallocation of individual industries to obtain the finalized set of cluster definitions $C^{* *}$.

\subsection{Step 5: Assessing Individual Clusters of Candidate $C^{*}$}

Because clustering analysis cannot perfectly substitute for expert judgment, the methodology concludes with a systematic correction of anomalies and characterization of the individual clusters in $C^{*}$, resulting in a finalized set of cluster definitions. Although Steps 1 to 4 systematically assign industries to clusters, the resulting $C$ s can be improved. Limitations in the underlying data may create spurious industry relatedness that will place some industries into 
clusters where they are not the best fit. Some clusters may contain conceptually distinct groups that may have not been separated because of the choice of initial number of groups (numc parameter); and other clusters may be better off combined. Step 5 allows us to examine the clusters in $C^{*}$ to assess whether there are industry outliers that are better placed into different clusters and whether to combine or break individual clusters to improve the coherence of the clusters. We can use our score approach to inform these expert-driven choices. Users can assess how certain changes impact the WCR scores of individual clusters and the validation scores of the cluster configuration relative to the initial values.

We define two types of possible outlier industries: systematic and marginal outliers. Systematic outlier industries are those with a low overall $\mathrm{WCR}_{\text {ic }}$ score (based on the average of standardized sub-scores for $\mathrm{WCR}^{\mathrm{LC}-E m p}, \mathrm{WCR}^{\mathrm{LC}-E s t}, \mathrm{WCR}^{\mathrm{IO}}$, and $\left.\mathrm{WCR}^{\mathrm{Occ}}\right) \cdot{ }^{19}$ Systematic outliers are identified and corrected with a simple sub-process. They are identified based on two criteria: the industry $\mathrm{WCR}$ is low relative to other clusters (i.e., $\mathrm{WCR}_{\text {ic }}$ is below the 75 th percentile value of $\mathrm{BCR}_{\mathrm{i}}$ ); or $\mathrm{WCR}$ is low relative to other industries in the same cluster (i.e., $\mathrm{WCR}_{\mathrm{ic}}$ is two standard deviations below the average $\mathrm{WCR}_{\mathrm{ic}}$ ). Then the systematic outliers are reassigned to the cluster where their WCR is highest. This sub-process is iterated several times until there are no systematic outliers.

Marginal outlier industries are those industries that, even with a high $\mathrm{WCR}_{\mathrm{ic}}$, could be conceptually better in another cluster. These outliers are often the result of limitations in the underlying data. ${ }^{20}$ For example, Men's and Boy's Clothing Manufacturing industries (NAICS 315221-31525) are in the Printing Services cluster for $C^{*}$, but they likely best belong to an Apparel cluster. Identifying these marginal outliers requires examining each cluster and analyzing the main product/service lines of the industries based on the detailed definitions offered by the NAICS system. The outliers are reallocated to their "next best" cluster using the

\footnotetext{
${ }^{19}$ The WCR score is based on these four sub-scores to have a more robust score that captures multiple inter-industry linkages within the cluster.

${ }^{20}$ In a few cases, the input-output link between two industries may be overestimated due to the level of aggregation of underlying data and/or due to our symmetric measure of $I O$ links. For example, R\&D industries (NAICS 541700) appear very highly linked to Water Transportation (NAICS 483000) industries because Water Transportation supplies a large percentage of its output to R\&D industries. This induces the R\&D industries to be grouped with Water Transportation if input-output links are considered in the similarity matrix. For industries where the underlying input-output data is highly aggregated and for industries with very high input-output links in the cluster, we check that these industries also fit well in their cluster based on the other measures $(L C$ and $O c c)$.
} 
$\mathrm{WCR}_{\mathrm{i}}$ scores. Reallocated marginal outliers can be easily tracked and documented so that the process is transparent.

Once we correct industry outliers, we then examine whether some individual clusters should be combined or partitioned. If two individual clusters have very high BCR and they do not seem conceptually different, they could be combined. In contrast, some individual clusters could be partitioned if we find clear conceptual and relatedness differences among certain subgroups of industries in a cluster. Because of these corrections, the initial number of clusters (numc) and the number of clusters in the finalized set of cluster definitions may differ.

After all five steps in the cluster algorithm are complete, we are able to recommend a final set of benchmark cluster definitions $C^{* *}$ (the BCD). We explain the main findings and the proposed new cluster definitions in the next Sections.

\section{Generating and Assessing Cluster Configurations}

We apply the clustering algorithm to generate 713 different cluster configurations that group 778 6-digit NAICS industries using 2009 U.S. data. These configurations are based on 13 different similarity matrices $\left(M_{i j}\right)$ and the parameter and clustering function choices discussed in the prior section $\left(C=F\left(M_{i j}, \beta\right)\right)$. As illustrated in Table 1, some $C$ s are generated using unidimensional matrices (e.g., $L C$-Emp) and others using multidimensional matrices (e.g., $L C$ $I O-O c c)$. We then generate the validation scores for each configuration to assess their relative quality. In this section, we use the scores to compare $C$ s generated using different similarity matrices. We then explain the properties of the proposed candidate $C^{*}$ that will be subject to assessment and adjustments of individual clusters in the last step of the algorithm to obtain the BCD.

Validation Scores by Choice of Similarity Matrix. Through our algorithm, we can compare how well the configurations derived from different similarity matrices perform in the validation scores. We can then assess which similarity matrices seem to result in cluster configurations that capture the broadest range of inter-industry linkages and potential externalities (e.g., demand, supply, skills, knowledge, and others).

We use our score function to compare $C$ s generated by either a unidimensional similarity matrix (LC-Emp, LC-Est, COI, IO, Occ) or the multidimensional LC-IO-Occ matrix. Each of these matrices can be used to create a number of different $C$ s by changing the type of clustering 
function and/or the parameter choices. For example, there are 31 s generated using a hierarchical function, $M_{i j}=L C-I O-O c c$, and 31 different values for the number of clusters (numc). We then assess the average quality of $C$ s generated with the same similarity matrix. The analysis is shown in Table 6, which reports the mean validation score (VS) and the mean validation subscores $\left(\mathrm{VS}^{\mathrm{LC}-\mathrm{Emp}}, \mathrm{VS}^{\mathrm{LC}-\mathrm{Est}}, \mathrm{VS}^{\mathrm{IO}}\right.$, and $\mathrm{VS}^{\mathrm{Occ}}$ ) by similarity matrix.

If we want to capture various inter-industry linkages within clusters, then $C$ s with higher overall validation scores will be preferred. We find that $C$ s generated with the $L C-I O-O c c$ matrix have, on average, statistically significant higher VS scores than other $C$ s generated based on unidimensional matrices. For example, the mean VS of $C \mathrm{~s}(L C-I O-O c c)$ is 76 , and the next best mean VS is 71 for $C \mathrm{~s}(L C$-Est) (Table 6). This difference in the means is statistically significant at $1 \%{ }^{21}$ The matrix $L C-I O-O c c_{i j}$ seems to generate meaningful sets of cluster definitions that capture a broad set of industry interdependencies. One of the $C$ s generated with this matrix is the proposed candidate $C^{*}$, which is the basis for our final set of cluster definitions.

We can also examine how other model choices influence the validation scores. While we cannot estimate the optimal number of groups $(n u m c)$ for a good set of cluster definitions, we can evaluate whether some numc values result in higher validation scores. For example, we find that validation scores for $C$ s with 40-to-49 clusters are higher than the validation scores for configurations that have either fewer (30-to-39) or more (50-60) clusters. This type of analysis can help users identify good parameter values for their clustering models.

Choosing the Candidate Configuration $C^{*}$. The choice of $C^{*}$ depends primarily on the validation scores. Those configurations with highly ranked scores for both VS-Cluster and VSIndustry (i.e., top-40 rankings in both scores across the $713 C \mathrm{~s}$ ) are the candidates, $C^{*}$ s. There are 24 candidates (see Table 7). Then the configuration with the maximum overall validation score $V S$ is the proposed candidate $C^{*}$. The $C^{*}$ is generated using a hierarchical clustering function with 47 clusters and the multidimensional similarity matrix LC-IO-Occ. This configuration has the highest validation score across all the $C$ s, with a score of $77.7 \%$ (see Table 5 for all the scores and sub-scores for $C^{*}$ ).

\footnotetext{
${ }^{21}$ Some studies may be interested in the sets of clusters that best capture a particular measure. Cluster configurations that are generated based exclusively on one particular measure tend to have better sub-scores in that particular measure. That is the case for $C$ s generated using $L C$-Emp, $L C$-Est, or $O c c$, but not for $C$ s generated based on $I O$. Using $C \mathrm{~s}(O c c)$ as an example, in Table 6 these $C \mathrm{~s}$ have a mean validation sub-score $\mathrm{VS}^{\mathrm{Occ}}$ higher than that of $C \mathrm{~s}(L C-I O-O c c)$ (99 versus 95$)$; but do significantly worse than $C \mathrm{~s}(L C-I O-O c c)$ in the other sub-scores.
} 
For sensitivity, we assess the robustness of the candidate $C^{*}$ by comparing its overlap to the other 23 promising configurations. Table 7 shows that on average $C^{*}$ has a high overlap of $77.6 \%$ with these other $C \mathrm{~s}$, indicating that they tend to provide very similar groupings of industries. The configuration $C^{*}$ will be subject to assessment and improvement of individual clusters in Step 5 to derive $C^{* * *}$.

\section{Proposed Set of Benchmark Cluster Definitions $\mathrm{C}^{* *}$}

Our methodology concludes with an assessment and correction of the individual clusters in $C^{*}$ to derive the finalized set of cluster definitions. We explain this process here, present a summary overview of the $\mathrm{BCD}$, and illustrate a few selected clusters. A detailed overview of the cluster definitions, with a description of each cluster, associated industry NAICS codes, summary calculations of the fit of each industry within its cluster, and a full explanation of the process to get to these clusters, is available in the supplemental online Technical Appendix. ${ }^{22}$

The proposed set of cluster definitions $C^{* *}$ has 51 clusters (see Table 8). In this set, 7 industries are systematic outliers and 125 industries are marginal outliers that were re-allocated into other clusters. ${ }^{23}$ While we started with 47 clusters in $C^{*}$, our final set of definitions has 51 clusters because we partitioned and combined some clusters to improve the coherence and usefulness of the cluster definitions. These modifications had a trivial effect on the VS score, which is $78 \%$ in $C^{* *}$ and $C^{*}$ (see Tables 5 and 10 ).

There are four cases where the algorithm divided industries into two clusters, but we created a single combined cluster because they had high Between Cluster Relatedness and seemed conceptually similar. Specifically, we combined the following pairs of clusters into an individual cluster: two textile clusters, two financial services clusters, two food clusters, and two upstream metal manufacturing clusters.

We also partitioned the original clusters in seven cases: six individual clusters were each partitioned into two clusters, and one cluster was partitioned into three. These partitions are

\footnotetext{
${ }^{22}$ The cluster definitions and the Technical Appendix are available at the U.S. Cluster Mapping website (http://clustermapping.us).

${ }^{23}$ The correction of marginal outlier industries may not improve the overall VS score since some industries are moved to clusters with lower $\mathrm{WCR}_{\mathrm{i}}$ than the original cluster. Most industries are moved to clusters with high relative $\mathrm{WCR}_{\mathrm{i}}$ scores. Specifically, around $40 \%$ of industries are re-allocated into a new cluster where they have a $\mathrm{WCR}_{\text {ic }}$ rank of 1 (best fit out of 51 clusters). A list of the marginal industries and their original and destination clusters can be accessed at the online Technical Appendix.
} 
supported by sensitivity analysis, and the new clusters have better properties $\left(\mathrm{WCR}_{\mathrm{c}}\right)$ than their original larger cluster. We separated Downstream Chemical Products from Biopharmaceuticals as supported by the underlying data and expert opinion. By doing this, we create narrower clusters that focus on different markets. Similarly, we separated the Downstream Metal Products cluster from the original Production Technology cluster, Leather and Related Products from the original Apparel cluster, and Coal Mining from Electric Power Generation and Transmission; the Mining cluster was partitioned into Metal Mining and Nonmetal Mining clusters. One partition happened systematically when we slightly increased the parameter value for the number of initial clusters (all else being equal): the Performing Arts cluster was separated from the original Marketing, Design, and Publishing. Finally, the original Lighting and Electrical Equipment cluster was partitioned into three clusters: the focal Lighting and Electrical Equipment, Medical Devices, and Recreational and Small Electronic clusters. While these clusters share skills, they are distinct groups. We explain these three clusters below.

After this process of assessment and correction of individual clusters, we finalize the characterization of clusters in $C^{* *}$ with the creation of names and conceptual subcategories (termed "subclusters") to help describe the content of each cluster. These subclusters are based mainly on industry definitions.

Table 8 offers a summary overview of the clusters in $C^{* *}$ (the BCD), with information by cluster on the number of industries, the average WCR score, and sub-scores. All the individual clusters have a high WCR score, but there is variation across clusters with Tobacco, Music and Sound Recording, and Jewelry and Precious Metals having the highest scores. Most clusters have an average WCR score greater than the maximum BCR score (i.e., WCR Rank of one).

Cluster Examples. We illustrate the BCD with number of clusters that differ in the types of industries included (e.g., different 3-digit NAICS) and in the types of corrections undertaken in Step 5 to provide additional insights into the cluster definitions.

Aerospace Vehicles and Defense Cluster (Table 9.1). This cluster includes establishments that manufacture aircraft, space vehicles, guided missiles, and related parts. It was systematically generated by Steps 1 to 3 of our algorithm, and contains seven industries in two different 3-digit NAICS (336 and 334). These industries can be categorized into three sub-clusters: Aircraft, Missiles and Space Vehicles, and Search and Navigation Equipment. All the industries fit best in this cluster as compared to being placed in any of the remaining 50 clusters (i.e., the rank for 
each industry based on $\mathrm{WCR}_{\mathrm{ic}}$ score equals 1 ). The industry with the highest WCR score is Aircraft Manufacturing (NAICS 315999), suggesting that this is a focal activity with relevant links to the other industries within the cluster. As an example of the cluster's distribution over U.S. regions, Figure 1 shows the Economic Areas that are highly specialized in this cluster, including, among many others, Seattle-Tacoma-Olympia, WA; Wichita-Winfield, KS; and Dallas-Fort Worth, TX.

Oil and Gas Production and Transportation Cluster (Table 9.2). This cluster includes firms involved in locating, extracting, refining, and transporting oil and gas. It contains 12 industries in six different 3-digit NAICS. The focal industry here is Petroleum Refineries (NAICS 324110). The mix of manufacturing and service industries in this cluster (and in other ten clusters) contrasts with the measurement of related economic activity used in other papers. For example, Frenken et al. (2007) develop a meaningful conceptual distinction of regional diversity in related economic activity versus diversity in unrelated economic activity. They classify industries in service and manufacturing as unrelated, which may not be the case for some clusters. $^{24}$

Insurance Services Cluster (Table 9.3). The firms in this cluster provide a range of insurance products as well as insurance support services. It contains eight service industries and is one of three clusters that is exactly equivalent to a 3-digit NAICS group (524). Insurancerelated services (e.g., Claims Adjusting, NAICS 524291; All Other Insurance Related Activities, NAICS 524298) is a focal part of the cluster, supporting a broad range of insurance types.

Medical Devices; Lighting and Electrical Equipment; and Recreational and Small Electric Goods Clusters (Tables 9.4-9.6). The algorithm originally grouped all three clusters into one large cluster. Using expert judgment, we separated the overall cluster into three based primarily on the NAICS definitions. We checked that the $\mathrm{WCR}_{\mathrm{c}}$ of each of the new clusters improved or changed minimally relative to the score of the initial larger cluster, and that their $\mathrm{WCR}_{\mathrm{c}}$ rank is 1 (Table 8$) .{ }^{25} \mathrm{We}$ also examined the geographic concentration of the three cluster

\footnotetext{
${ }^{24}$ Frenken et al. (2007) define related variety in a region by examining the diversity of industries within a given two-digit industry class (i.e., entropy at the five-digit level industries within each two-digit industry class); and find that related diversity enhances regional employment growth.

${ }^{25}$ Specifically, in the initial $C^{*}$ with 47 groups (and after correcting the industry outliers), the $\mathrm{WCR}_{\mathrm{c}}$ of the original cluster was 1.5, while each of the $\mathrm{WCR}_{\mathrm{c}}$ of the partitioned clusters was 1.7 for Lighting and Electrical Equipment, 2.3 for Medical Devices, and 1.5 for Recreational and Small Electric Goods.
} 
categories across EA regions as an additional criterion, and concluded that they have different geographic concentration patterns.

As suggested by their descriptions, the three clusters are conceptually different. The Medical Devices cluster (Table 9.4) consists of firms that manufacture different medical devices and supplies. It has five industries representing two 3-digit NAICS codes (333 and 339). Firms in the Lighting and Electrical Equipment cluster (Table 9.5) are not involved in manufacturing medical devices, but do manufacture other electrical equipment and electronic components. It is a larger cluster, consisting of 15 industries representing one 3-digit NAICS code (335). Finally, firms in the Recreational and Small Electric Goods cluster (Table 9.6) are related to those in the Lighting and Electrical Equipment cluster, but the focus is different. These establishments manufacture end-use products for recreational, decorative, and office purposes. There are 15 industries that represent five different 3-digit NAICS codes.

\section{Comparison of our $C^{* *}$ and Existing Sets of Cluster Definitions}

Using the clustering algorithm, we can assess the relative performance of our proposed set of benchmark cluster definitions $C^{* *}$ and other existing sets of cluster definitions: NAICS-3, Porter (2003), and Feser (2005). We use the mutually exclusive sets of cluster definitions offered by Porter (2003) and Feser (2005) since the differences are more readily apparent when each industry is assigned to one cluster, and their overlapping clusters rely on having well-defined mutually exclusive clusters. Before providing the details of the comparisons, it is important to clarify that the number of industries and the number of groups are different across the four sets. Our $C^{* *}$ includes 778 industries and 51 clusters, NAICS-3 grouping includes 778 industries and 66 clusters, Porter's (2003) set includes 685 industries and 41 traded clusters, and Feser's (2005) set includes 910 industries and 44 clusters (excluding farming and a few other industries due to data limitations). ${ }^{26}$

The validation scores for the selected sets of cluster definitions are presented in Table 10. Our analysis shows that a definition based on grouping industries with the same 3-digit NAICS code performs relatively poorly when trying to capture a broad set of industry interdependencies. The overall validation score of NAICS-3 is the lowest (58) not only among the existing sets, but

\footnotetext{
${ }^{26}$ One of the clusters in Feser's (2005) set is Farming, which is excluded from the CBP data; therefore, we focus the analysis on the other 44 clusters and 910 industries (out of 969 industries) that we can bridge into 2007 NAICS codes and CBP data. The larger number of industries in Feser (2005) is in part due to the inclusion of local health services.
} 
also among all the cluster configurations $(C s)$ generated by the algorithm. The NAICS-3 groupings do poorly in most sub-scores except for occupational linkages. The low validation scores are perhaps not surprising, since the industry code system groups industries based on similarities in products or services, not based on broader inter-industry complementarities. This suggests that many studies that classify industries from different parts of the industry code as unrelated may fail to capture relevant inter-industry linkages.

In Table 10, we find that $C^{* *}$ scores better in capturing a broad set of industry interdependencies than any of the other sets of clusters. $C^{* *}$ receives the highest validation score (and highest VS-Cluster and VS-Industry scores) with a VS value of 78 as compared to 73 for Porter (2003), 69 for Feser (2005), and 58 for NAICS-3. Furthermore, the validation score of $C^{* *}$ ranks second across the $713 C$ s generated by the algorithm. $C^{* * *}$ also seems to perform well in particular inter-industry measures. Specifically, $C^{* *}$ scores better or the same as the three other sets in the validation sub-scores for pairwise industry co-location of the number of establishments $\left(V S^{L C-E s t}\right)$, input-output links $\left(V S^{I O}\right)$, and shared labor occupations $\left(V S^{O c c}\right)$. Porter (2003) set scores highest in the validation sub-score for pairwise industry co-location of employment $\left(V S^{L C-E m p}\right)$, but with little difference from the $C^{* *}$ score (67 versus 66$)$. The Feser (2005) set does relatively worse than $C^{* *}$ in the $L C$ and $I O$ sub-scores. The lower validation subscore for $I O$ links could be due to the fact that Feser's (2005) set of clusters uses a particular indirect $I O$ link measure that is different from the one used in this paper (i.e., his measure captures the percent of meaningful suppliers and buyers in common for a pair of industries rather than the direct selling and buying to and from each other). Overall, these findings suggest that the clusters in our proposed set of benchmark cluster definitions contain industries that are meaningfully related, and may facilitate externalities of various types.

We can also analyze the industry overlap between the clusters in $C^{* *}$ and the clusters in the other three sets of cluster definitions to evaluate whether different clustering methods tend to generate similar clusters. In each case, we examine the overlap for the sub-set of industries in common with $C^{* *}$. For example, $C^{* *}$ and NAICS-3 definitions have 778 industries in common, which belong to 51 clusters in $C^{* *}$ and 66 clusters in NAICS-3. We then assess if the industries are grouped in similar clusters using our overlap score (see Section 3.4). We compute the overlap score in each direction (i.e., $C^{* * *}$ to NAICS-3 and NAICS-3 to $C^{* *}$ ) and then take the average in both directions. The findings are presented in Table 11. The average industry overlap is $61 \%$ 
between $C^{* *}$ and NAICS-3, which means that on average a pair of clusters shares $61 \%$ of their industries. Only three clusters are identical in both sets (100\% overlap): Environmental Services (NAICS-562); Insurance Services (NAICS-524; Table 9.3); and Paper and Packaging (NAICS322). ${ }^{27}$ Similarly, the average cluster overlap is $57 \%$ between $C^{* *}$ and Porter's (2003) set, and $54 \%$ between $C^{* *}$ and Feser's (2005) set. While there is overlap between sets, the scores indicate that the clusters in the BCD are meaningfully different from those in the other existing sets.

\subsection{Research and Policy Applications for the BCD}

What constitutes a good set of cluster definitions depends on the particular research or policy question. We implement our clustering algorithm to offer a set of benchmark cluster definitions that captures numerous inter-industry linkages and could facilitate externalities of various types (e.g., skills, supply, demand, and others).

For research questions that focus on a particular type of inter-industry link (e.g., occupational links and potential labor market pooling benefits), groupings that better capture that specific link may be preferred. For example, if the policy goal is to promote training and skills that could be shared by industries with similar labor needs, cluster configurations that best capture occupational links will be useful.

However, if the goal is to promote multiple complementarities across industries, we believe our BCD may be more useful. Industries within our cluster categories are highly related based on a mix of various links. Some industries in a cluster may have strong skill links, while other industries may be closely related by $I O$, technology, and/or other types of links. Policies that focus on improving a specific link for a sub-set of industries within the cluster (e.g., training and skills shared by some industries) can facilitate complementarities of many types among all industries in the cluster.

We believe our proposed BCD is particularly important for studying the economic development of regions. We map the finalized set of cluster definitions into different regional units (Metropolitan Statistical Areas (MSAs), Economic Areas (EAs), and States) over time, creating a regional cluster dataset that allows for a systematic comparison of the cluster composition of regions using different metrics (e.g., employment, specialization, wages, and number of establishments). For example, Figure 1 shows the top regional Aerospace Vehicles

\footnotetext{
${ }^{27}$ The number of different 3-digit NAICS in a cluster in $C^{* *}$ is on average 2.7 .
} 
and Defense clusters across Economic Areas in 2010. This database is publicly available at the U.S. Cluster Mapping website.

For a particular cluster category, we can assess its presence in a region and examine what industries are under-represented (or non-existing) in the region as compared to the national cluster or as compared to similar clusters in other regions. These comparisons can then be the focus of key research and policy actions. To design policies that help a regional cluster, we need to examine why certain industries are under-represented or under-performing. Several explanations are plausible: the lack of skills, inputs, technology, sophisticated demand, and/or institutions for collaboration. Other methods that focus on examining region-specific links among firms and individuals in clusters could complement our benchmark cluster definitions and offer important insights into the mechanism at play in a particular regional cluster.

The ability to compare a cluster across regions can also facilitate the evaluation of regional cluster policies (Feldman et al. 2012). For example, we could identify a few regional clusters that look very similar in a base year in terms of various cluster attributes (size, specialization, number of firms, industry composition, etc.), but where one cluster is the target of a relevant investment (say a private-public grant) and the others are not. We can then assess if over time we observe differences in the composition and performance of the treated regional cluster relative to the others. In addition, researchers can use our clustering method and the BCD-based database to examine relevant questions on the role of clusters in the performance of regions and firms.

\section{Conclusion}

In order to compete more effectively, regions need to understand their cluster strengths as compared to those of other regions. To make this comparison, a set of regionally comparable cluster definitions that marks the industry boundaries of each cluster is necessary. This paper responds to this need by providing a clustering methodology to generate and assess sets of cluster definitions. In our algorithm, each cluster configuration is generated by a clustering function that uses as inputs a particular inter-industry similarity matrix and well-specified parameter choices. The clustering algorithm provides scores that assess the quality of each configuration. This allows us to identify the candidate configuration that best captures multiple types of inter-industry links. The methodology concludes with a correction of anomalies of the 
individual clusters in the most promising configuration to determine our finalized set of cluster definitions.

Using U.S. data, we implement the clustering algorithm to generate a transparent set of benchmark cluster definitions that captures many inter-industry interdependencies. The proposed definitions use measures of inter-industry linkages based on the co-location patterns of employment and establishments, input-output linkages, and shared labor occupations. The BCD contains 51 clusters that can be mapped consistently into U.S. regions to create a regional cluster database.

With an updateable algorithm for defining and assessing alternative cluster definitions, a number of extensions are possible. First, we can add additional inter-industry similarity matrices as they become available (e.g., specific measures of knowledge linkages or labor flows among industries) to generate improved cluster definitions.

Second, while the analysis here focuses on mutually exclusive clusters, the methodology also provides scores of the relatedness between any pair of clusters and between any industry and any cluster. These scores are based on various inter-industry linkage measures. Thus, we can assess which mutually exclusive clusters are meaningfully related (e.g., industries in the Financial Services cluster and in the Insurance Services cluster are highly related). We can also develop overlapping cluster definitions by adding secondary industries that are highly related to the industries that constitute each (mutually exclusive) cluster (Porter, 2003; Feser, 2005). Defining measures of the relatedness among clusters is important since economies of agglomeration arise across related clusters as well as within individual clusters (Delgado, Porter, and Stern, 2014).

Third, our clustering method can be applied to other countries using their specific data. Defining clusters is best undertaken using data from large and diverse economies with numerous highly integrated regions. Since the U.S. is a large and diverse economy, the U.S. benchmark cluster definitions are a good starting point, especially for economies that lack the data needed to implement the clustering methodology. However, there are some limitations on using the BCD in other economies that are weighted toward economic activities that are less prevalent in the United States (e.g., ship building) or that are not well captured by U.S. data (e.g., farming). They may also be less useful in countries with a lower level of technological development, but here, our definitions offer important insights into how clusters could form with reduced internal 
barriers to trade and technological improvements. Finally, the BCD will be especially useful for countries with an industry code schema similar in detail to the one in the United States (e.g., Mexico and Canada). It can also be applied with higher aggregation to a large set of countries through matching the U.S. NAICS code to the U.N. International Standard Industrial Classification (ISIC). Definitions based on ISIC would facilitate an examination of the trade and foreign direct investment links of clusters across countries (e.g., Bathelt and Li, 2013; Delgado, Kyle, and McGahan, 2013).

A fourth extension is the further examination of local industries (e.g., retail industries, hospitals) and their linkages with traded regional clusters. Our clustering analysis excludes local industries because they do not geographically concentrate, but rather focus on serving a region's population. Also, within a region certain local industries (e.g., local business services, retail activities) can geographically concentrate, which has implications for policy.

Fifth, the algorithm can be used to track the evolution of the industry boundaries of clusters over time. For example, while IT and analytical instruments industries are highly related today, they may have been less complementary a decade or two ago. The emergence and evolution of clusters have not been widely studied due to lack of data (Swann, 1998; Porter, 1998; Bathelt and Boggs, 2003; Klepper, 2010). However, an understanding of cluster emergence and relatedness could have wide-ranging implications for forward-looking regional strategy.

Another area for future research is the development of methods to adapt cluster definitions to specific regions (i.e., the industry boundaries of a cluster can sometimes vary by region). For example, regional input-output tables could be used to measure region-specific buyer-supplier linkages in clusters.

Finally, our benchmark cluster definitions can be mapped into continuous spatial units as well as administrative units (e.g., MSAs, EAs, and States). We could then analyze the microgeography of clusters within (and across) jurisdictions (e.g., Duranton and Overman, 2005; Kerr and Kominers, 2010; Alcacer and Zhao, 2013). For example, in a particular Economic Area (e.g., Los Angeles, CA), we could assess whether a cluster category is geographically separated in distant parts within the region or whether the whole cluster is closely co-located. Understanding the micro-geography of clusters can help inform policies to facilitate the connectivity of firms and supportive institutions within clusters. 
The BCD, combined with other available data sources, can be used to greatly inform economic development. For example, using the BCD and other data sources, the U.S. Cluster Mapping Project has created a regional cluster dataset together with multiple regional performance and business environment indicators (e.g., employment, specialization, wages, and number of establishments). The Project provides a powerful tool for researchers and policymakers, and offers a new interactive tool for practitioners and firms looking to identify opportunities in regions and design cluster-based regional economic development policies. The tool also maps the cluster composition of regions to encourage connections previously not identified. 


\section{References}

Alcacer, J. and W. Chung, 2014, "Location Strategies for Agglomeration Economies," Strategic Management Journal (forthcoming).

Alcacer, J. and M. Zhao, "Zooming In: A Practical Manual for Identifying Geographic Clusters," Harvard Business School Working Paper, No. 14-042, November 2013.

Bathelt, H. and J.S. Boggs, 2003, "Toward a Reconceptualization of Regional Development Paths: Is Leipzig's Media Cluster a Continuation of or a Rupture with the Past?," Economic Geography 79, pp. 265-93.

Bathelt, H. and P.F. Li, 2013, "Global Cluster Networks - Foreign Direct Investment Flows From Canada to China," Journal of Economic Geography, 13. doi: 10.1093/jeg/lbt005.

Bathelt, H., A. Malmberg, and P. Maskell, 2004, "Clusters and Knowledge: Local Buzz, Global Pipelines, and the Process of Knowledge Creation," Progress in Human Geography, 28 (1), pp. 31-56.

Bloom, N., M. Schankerman, and J. Van Reenen, 2012, "Identifying Technology Spillovers and Product Market Rivalry," Econometrica, 81 (4), pp. 1347-93.

Bresnahan, T., A. Gambardella (eds.), 2004, Building High-Tech Clusters. Silicon Valley and Beyond. Cambridge University Press, New York.

Cortright, J., 2006, "Making Sense of Clusters: Regional Competitiveness and Economic Development," The Brookings Institution Metropolitan Policy Program, http://www.brookings.edu/reports/2006/03cities_cortright.aspx.

Cortright, J., 2010, "The Athletic and Outdoor Industry Cluster: A White Paper," Impresa Economics.

Delgado, M., M. Kyle, and A.M. McGahan, 2013, "Intellectual Property Protection and the Geography of Trade," Journal of Industrial Economics, 61 (3), pp. 733-62.

Delgado, M., M.E. Porter, and S. Stern, 2010, "Clusters and Entrepreneurship," Journal of Economic Geography, 10 (4), pp. 495-518.

Delgado, M., M.E. Porter, and S. Stern, 2014, "Clusters, Convergence, and Economic Performance," Research Policy, forthcoming.

Duranton, G. and H.G. Overman, 2005, "Testing for Localization Using Micro-Geographic Data," Review of Economic Studies, 72 (4), pp. 1077-1106.

Ellison, G. and E. Glaeser, 1997, "Geographic Concentration in U.S. Manufacturing Industries: A Dartboard Approach," Journal of Political Economy, 105, pp. 889-927.

Ellison, G., E. Glaeser, and W. Kerr, 2010, "What Causes Industry Agglomeration? Evidence from Coagglomeration Patterns," The American Economic Review, 100 (3), pp. 11951213.

Everitt, B.S., S. Landau, M. Leese, and D. Stahl, 2011, Cluster Analysis, 5th Edition, John Wiley \& Sons, Ltd., Chichester, UK.

Feldman, M.P. and D. Audretsch, 1999, "Innovation in Cities: Science-based Diversity, Specialization, and Localized Competition," European Economic Review, 43, pp. 40929.

Feldman, M.P., J. Francis, and J. Bercovitz, 2005, "Creating a Cluster While Building a Firm: Entrepreneurs and the Formation of Industrial Clusters," Regional Studies, 39 (1), pp. $129-41$.

Feldman, M.P., A.G. Reed, L. Lanahan, G. McLaurin, K. Nelson, and A. Reamer, 2012, "Innovative Data Sources for Economic Analysis," e-book. 
Feser, E.J., 2005, "Benchmark Value Chain Industry Clusters for Applied Regional Research," Regional Economics Applications Laboratory, University of Illinois at UrbanaChampaign.

Feser, E.J. and E.M. Bergman, 2000, "National Industry Cluster Templates: A Framework for Applied Regional Cluster Analysis," Regional Studies, 34 (1), pp. 1-19.

Feser, E.J., H. Renski, and H. Goldstein, 2008, "Clusters and Economic Development Outcomes," Economic Development Quarterly, 22 (4), pp. 324-44.

Feser, E.J., H. Renski, and J. Koo, 2009, "Regional Cluster Analysis with Interindustry Benchmarks," in S.J. Goetz, S.C. Deller, and T.R. Harris (eds.), Targeting Regional Economic Development, pp. 213-38.

Frenken, K., F.G. Van Oort, and T. Verburg, 2007, "Related Variety, Unrelated Variety, and Regional Economic Growth," Regional Studies, 41 (5), pp. 685-97.

Glaeser, E.L. and W.R. Kerr, 2009, "Local Industrial Conditions and Entrepreneurship: How Much of the Spatial Distribution Can We Explain?," Journal of Economics and Management Strategy, 18 (3), pp. 623-63.

Grimmer, J. and G. King, 2011, "General Purpose Computer-assisted Clustering and Conceptualization," Proceedings of the National Academy of Sciences, 108 (7), pp. 264350 .

Hidalgo, C.A., B. Klinger, A.L. Barabasi, and R. Hausmann, 2007, "The Product Space Conditions the Development of Nations," Science 317 (5837): 482-87.

Hill, E.W. and Brennan, J.F., 2000, "A Methodology for Identifying the Drivers of Industrial Clusters: The Foundation of Regional Competitive Advantage," Economic Development Quarterly, 14: 65-96.

Jaffe, A., M. Trajtenberg, and R. Henderson, 1993, "Geographic Localization of Knowledge Spillovers as Evidenced by Patent Citations," Quarterly Journal of Economics, 108, pp. 577-98.

Johnson, K.P. and J.R. Kort, 2004, "2004 Redefinition of the BEA Economic Areas," at http://www.bea.gov/scb/pdf/2004/11November/1104Econ-Areas.pdf.

Klepper, S., 2010, "The Origin and Growth of Industry Clusters: The Making of Silicon Valley and Detroit," Journal of Urban Economics, 67 (1), pp. 15-32.

Kerr, W. and S. Kominers, 2010, "Agglomerative Forces and Cluster Shapes," NBER Working Paper 16639.

Koo, J., 2005a, "How to Analyze the Regional Economy with Occupation Data," Economic Development Quarterly, 19: 356-72.

Koo, J., 2005b, "Knowledge-based Industry Clusters: Evidenced by Geographical Patterns of Patents in Manufacturing," Urban Studies, 42: 1487-505.

Krugman, P., 1991, "Increasing Returns and Economic Geography," Journal of Political Economy 99 (3), pp. 483-99.

Lorenzen, M. and R. Mudambi, 2013, "Clusters, Connectivity, and Catch-up: Bollywood and Bangalore in the Global Economy," Journal of Economic Geography, 13, pp. 501-34.

Marshall, A., 1920, Principles of Economics, London: MacMillan.

Markusen, A., 1996, "Sticky Places in Slippery Space: A Typology of Industrial Districts," Economic Geography, 72 (3), pp. 293-313.

Maskell, P. and A. Malmberg, 2007, "Myopia, Knowledge Development, and Cluster Evolution," Journal of Economic Geography, 7, pp. 603-18. 
Neffke, F. and M. Henning, 2013, "Skill-relatedness and Firm Diversification," Strategic Management Journal, 34 (3), pp. 297-316.

Neffke, F., M. Henning, and R. Boschma, 2011, "How Do Regions Diversify over Time? Industry Relatedness and the Development of New Growth Paths in Regions," Economic Geography, 87 (3).

Porter, M.E., 1990, The Competitive Advantage of Nations, Free Press, New York.

Porter, M.E., 1998, "Clusters and Competition: New Agendas for Companies, Governments, and Institutions," in M.E. Porter (ed.), On Competition, Harvard Business School Press, Boston, pp. 197-299.

Porter, M.E., 2003, “The Economic Performance of Regions," Regional Studies, 37, pp. 549-78.

Porter, M.E. and J. Ramirez-Vallejo, 2013, "The New Caroline Initiative," Harvard Business School, N9-713-462.

Rosenthal, S.S. and W.C. Strange, 2003, "Geography, Industrial Organization, and Agglomeration," Review of Economics and Statistics, 85, pp. 377-93.

Rosenthal, S.S. and W.C. Strange, 2004, "Evidence on the Nature and Sources of Agglomeration Economies," in J.V. Henderson and J.F. Thisse (eds.), Handbook of Regional and Urban Economics, vol. 4., Amsterdam: Elsevier North-Holland.

Saxenian, A., 1994, Regional Advantage: Culture and Competition in Silicon Valley and Route 128, Cambridge, MA: Harvard University.

Scherer, F.M., 1982, "Inter-industry Technology Flows and Productivity Growth," The Review of Economics and Statistics, 64 (4), pp. 627-34.

Sorenson, O. and P.G. Audia, 2000, "The Social Structure of Entrepreneurial Activity: Geographic Concentration of Footwear Production in the United States, 1940-1989," American Journal of Sociology, 106 (2), pp. 424-62.

Storper M., 1995, "The Resurgence of Regional Economies, Ten Years Later: The Region as a Nexus of Untraded Interdependencies, European Urban and Regional Studies, 2, pp. 191-221.

Storper, M. and T. Venables, 2004, "Buzz: Face-to-Face Contact and the Urban Economy," Journal of Economic Geography, 4 (4), pp. 351-70.

Swann, P., 1992, The Dynamics of Industrial Clusters, Oxford.

Swann, P., 1998, "Clusters in the U.S. Computing Industry," in Swann, P., M. Prevezer, and D. Stout (eds.), 1998, The Dynamics of Industrial Clustering: International Comparisons in Computing and Biotechnology, Oxford: Oxford University Press, pp. 76-105. 
Table 1: Examples of Cluster Configurations Generated

\begin{tabular}{|c|c|c|c|c|}
\hline \multirow[t]{2}{*}{ Similarity Matrix $\mathbf{M}_{\mathrm{ij}}$} & \multicolumn{2}{|c|}{ Parameter Choices $\beta$} & \multirow{2}{*}{$\begin{array}{c}\text { Clustering Function } \\
\qquad=\mathrm{F}\left(\mathrm{M}_{\mathrm{ij}}, \beta\right)\end{array}$} & \multirow[t]{2}{*}{ No. of $C \mathrm{~s}$} \\
\hline & No. Clusters (numc) & Data & & \\
\hline \multirow{3}{*}{ LC-Employment ${ }_{\mathrm{ij}}$} & $30-60$ & Raw & Hierarchical-Ward's & 31 \\
\hline & & Raw/Std & Kmean & 62 \\
\hline & & Raw/Std & Kmedian & 62 \\
\hline \multirow{3}{*}{ LC-Establishments $_{\mathrm{ij}}$} & $30-60$ & Raw & Hierarchical-Ward's & 31 \\
\hline & & Raw/Std & Kmean & 62 \\
\hline & & Raw/Std & Kmedian & 62 \\
\hline \multirow{3}{*}{ Labor Occupation $\left(\mathrm{Occ}_{\mathrm{ij}}\right)$} & $30-60$ & Raw & Hierarchical-Ward's & 31 \\
\hline & & Raw & Kmean & 31 \\
\hline & & Raw & Kmedian & 31 \\
\hline Input-Output $\left(\mathrm{IO}_{\mathrm{ij}}\right)$ & $30-60$ & Raw & Hierarchical-Ward's & 31 \\
\hline Coagglomeration Index & $30-60$ & Raw & Hierarchical-Ward's & 31 \\
\hline LC_IO_Occ $_{\mathrm{ij}}{ }^{*}$ & $30-60$ & Raw & Hierarchical-Ward's & 31 \\
\hline
\end{tabular}

${ }^{*}$ This $\mathrm{M}_{\mathrm{ij}}$ is an average of the (standardized) LC-Employment, LC-Establishments, IO, and Occ matrices. See Table A1 for a list of all the similarity matrices used. The Hierarchical function uses Ward's linkages.

Table 2: Descriptive Statistics for Similarity Matrices (778 industries (6-digit NAICS-2007 codes), 2009 data; $N=604,506$ )

\begin{tabular}{|c|c|c|c|c|c|c|}
\hline Similarity Matrices $\mathbf{M}_{\mathrm{ij}}$ & Mean & Std Dev & Min & Max & Median & Pctile90 \\
\hline LC-Employment (LC-Emp $\left.{ }_{\mathrm{ij}}\right)$ & 0.296 & 0.232 & -0.176 & 0.993 & 0.263 & 0.631 \\
\hline LC-Establishments (LC-Est ${ }_{\mathrm{ij}}$ ) & 0.519 & 0.259 & -0.174 & 0.998 & 0.555 & 0.840 \\
\hline Input-Output $\left(\mathrm{IO}_{\mathrm{ij}}\right)$ & 0.017 & 0.045 & 0 & 1 & 0.001 & 0.064 \\
\hline Labor Occupation $\left(\mathrm{Occ}_{\mathrm{ij}}\right)$ & 0.183 & 0.202 & -0.013 & 1 & 0.113 & 0.450 \\
\hline Coagglomeration Index $\left(\mathrm{COI}_{\mathrm{ij}}\right)$ & -0.000 & 0.010 & -0.051 & 0.372 & -0.000 & 0.007 \\
\hline LC-IO-Occ ${ }_{i j}^{*}$ & -0.002 & 0.646 & -1.438 & 6.716 & -0.037 & 0.801 \\
\hline
\end{tabular}

Notes: An observation is any pair of industries $(\mathrm{ij}, \mathrm{i} \neq \mathrm{j})$. ${ }^{*} \mathrm{LC}-\mathrm{IO}-\mathrm{Occ}_{\mathrm{ij}}$ is an average of the (standardized) LCEmployment, LC-Establishments, IO, and Occ.

Table 3: Correlation between Similarity Matrices (778 industries (6-digit NAICS-2007 codes), 2009 data; $\mathrm{N}=604,506$ )

\begin{tabular}{lcccccc}
\hline & LC-Emp & LC-Est & IO & Occ & COI & NAICS-3 \\
LC-Employment & 1.00 & & & & & \\
LC-Establishments & 0.77 & 1.00 & & & & \\
Input-Output & 0.16 & 0.13 & 1.00 & & & \\
Labor Occupation & 0.03 & 0.10 & 0.13 & 1.00 & & \\
Coagglomeration Index & 0.36 & 0.17 & 0.07 & 0.15 & 1.00 & \\
NAICS-3 $^{\text {LC-IO-Occ }}$ & 0.05 & 0.05 & 0.09 & 0.45 & 0.09 & 1.00 \\
\hline
\end{tabular}

Notes: An observation is any pair of industries $(\mathrm{ij}, \mathrm{i} \neq \mathrm{j})$. All coefficients are significant at $1 \%$ level. All variables are based on 2009 data except for IO, which is based on 2002 data. *NAICS-3 matrix is equal to 1 for a pair of industries with the same 3 -digit NAICS code (and 0 otherwise). 
Table 4: Descriptive Statistics: Validation Scores for Cluster Configurations (No. of $C s=713$ )

\begin{tabular}{|c|c|c|c|c|c|c|}
\hline Validation Scores & Description & Mean & Std Dev & Min & Max & Pctile90 \\
\hline VS-Cluster & $\begin{array}{l}\% \text { of clusters with high } \mathrm{WCR}_{\mathrm{c}} \text { (Average } \\
\text { of VS-Cluster sub-scores) }\end{array}$ & 73.9 & 4.8 & 63.5 & 83.9 & 80.4 \\
\hline VS-Industry & $\begin{array}{l}\% \text { of industries with high } \mathrm{WCR}_{\mathrm{ic}} \\
\text { (Average of VS-Industry sub-scores) }\end{array}$ & 66.3 & 3.1 & 56.9 & 74.2 & 70.2 \\
\hline VS & Average VS-Cluster and VS-Industry & 70.1 & 3.5 & 63.4 & 77.7 & 74.5 \\
\hline \multicolumn{7}{|c|}{ Sub-scores based on individual similarity matrix (LC-Emp, LC-Est, IO, or Occ) } \\
\hline VS-Cluster ${ }^{\text {LC-Emp }}$ & $\%$ of clusters with high WCR ${ }^{\text {LC-Emp }}$ & 76.7 & 14.9 & 50.0 & 100.0 & 96.9 \\
\hline VS-Cluster ${ }^{\text {LC-Est }}$ & $\%$ of clusters with high WCR ${ }^{\text {LC-Est }}$ & 71.4 & 11.0 & 50.0 & 96.7 & 89.5 \\
\hline VS-Cluster ${ }^{\mathrm{IO}}$ & $\%$ of clusters with high $\mathrm{WCR}^{\mathrm{IO}}$ & 68.3 & 15.9 & 41.7 & 98.3 & 94.1 \\
\hline VS-Cluster ${ }^{\text {Occ }}$ & $\%$ of clusters with high WCR ${ }^{\text {Occ }}$ & 79.3 & 18.2 & 47.3 & 100.00 & 100.0 \\
\hline VS-Industry ${ }^{\text {LC-Emp }}$ & $\%$ of industries with high WCR ${ }^{\text {LC-Emp }}$ & 70.6 & 16.0 & 45.9 & 97.8 & 92.9 \\
\hline VS-Industry ${ }_{\text {LC-Est }}$ & $\%$ of industries with high $\mathrm{WCR}^{\text {LC-Est }}$ & 68.9 & 13.4 & 45.6 & 95.2 & 88.7 \\
\hline VS-Industry ${ }^{\mathrm{IO}}$ & $\%$ of industries with high $\mathrm{WCR}^{\mathrm{IO}}$ & 54.9 & 12.1 & 40.3 & 80.4 & 75.7 \\
\hline VS-Industry ${ }^{\text {Occ }}$ & $\%$ of industries with high $\mathrm{WCR}^{\text {Occ }}$ & 70.8 & 19.1 & 46.5 & 99.8 & 98.3 \\
\hline
\end{tabular}

Table 5: Validation Scores (sub-scores) for Selected Cluster Configuration $C^{*}$ (778 industries)

\begin{tabular}{|c|c|c|c|}
\hline \multicolumn{4}{|c|}{$C^{*}=$ Hierarchical $(\mathrm{LC}-\mathrm{IO}-O c c, 47$ clusters) } \\
\hline Validation Sub-scores & $\begin{array}{c}\text { VS-Cluster } \\
\text { \% Clusters with high } \mathrm{WCR}_{\mathrm{c}}\end{array}$ & $\begin{array}{c}\text { VS-Industry } \\
\text { \% Industries with high } \mathrm{WCR}_{\mathrm{ic}}\end{array}$ & $\begin{array}{c}\text { VS } \\
\text { (Avg VS-Cluster, VS-Industry) }\end{array}$ \\
\hline $\mathbf{V S}^{\text {LC-Emp }}(\mathrm{Avg})$ & 67.0 & 61.7 & 64.4 \\
\hline WCR $>$ AvgBCR & 93.6 & 90.7 & 92.2 \\
\hline WCR $>$ Pctile95BCR & 40.4 & 32.6 & 36.5 \\
\hline $\mathbf{V} \mathbf{S}^{\text {LC-Est }}($ Avg) & 68.1 & 62.3 & 65.2 \\
\hline WCR $>$ AvgBCR & 89.4 & 91.0 & 90.2 \\
\hline WCR $>$ Pctile95BCR & 46.8 & 33.5 & 40.2 \\
\hline $\mathbf{V S}^{\mathbf{I O}}(\mathrm{Avg})$ & 92.6 & 78.0 & 85.3 \\
\hline WCR $>$ AvgBCR & 97.9 & 89.7 & 93.8 \\
\hline WCR $>$ Pctile95BCR & 87.2 & 66.3 & 76.8 \\
\hline $\mathbf{V S} \mathbf{S}^{\mathbf{O c c}}(\mathrm{Avg})$ & 98.9 & 92.8 & 95.9 \\
\hline $\mathrm{WCR}>\mathrm{AvgBCR}$ & 100.0 & 98.7 & 99.4 \\
\hline WCR $>$ Pctile95BCR & 97.9 & 86.9 & 92.4 \\
\hline Validation Scores & 81.6 & 73.7 & 77.7 \\
\hline Rank (1=best) & 14 & 4 & 1 \\
\hline
\end{tabular}

Notes: We compute to what extent individual clusters and industries in $C$ have Within Cluster Relatedness (WCR) greater than a Between Cluster Relatedness (BCR) cut-off value based on particular similarity matrices $\mathrm{M}_{\mathrm{ij}}$. We then average these sub-scores into the Validation Scores: VS=Avg(VS $\left.{ }^{\text {LC-Emp }}, \mathrm{VS}^{\mathrm{LC}-\mathrm{Est}}, \mathrm{VS}^{\mathrm{IO}}, \mathrm{VS}^{\text {Occ }}\right)$. The Validation Score Rankings are computed across 713 sets of cluster definitions. 
Table 6: Mean of Validation Score (and sub-scores) by Selected Similarity Matrices $\left(\mathrm{M}_{\mathrm{ij}}\right)$

Validation Score

Validation Sub-scores

VS

\begin{tabular}{lcccccc}
$\mathbf{M}_{\mathbf{i j}}$ & $\mathbf{N o .} \boldsymbol{C} \mathbf{s}\left(\mathbf{M}_{\mathbf{i j}}\right)$ & $($ Avg sub-scores $)$ & $\mathbf{V S}^{\mathbf{L C}-E m p}$ & $\mathbf{V S}^{\mathbf{L C}-E s t}$ & $\mathbf{V S}^{\mathbf{I O}}$ & $\mathbf{V S}^{\mathbf{O c c}}$ \\
\hline LC-IO-Occ & 31 & 76 & 62 & 64 & 84 & 95 \\
\hline LC-Emp & 155 & 67 & 94 & 70 & 50 & 54 \\
LC-Est & 155 & 71 & 79 & 89 & 53 & 63 \\
IO & 31 & 70 & 56 & 59 & 85 & 82 \\
Occ & 93 & 67 & 55 & 55 & 58 & 99 \\
COI & 31 & 65 & 89 & 70 & 50 & 53 \\
\hline
\end{tabular}

Notes: Validation scores and sub-scores take value [0,100]. The differences in the means of the validation scores and sub-scores of $C \mathrm{~s}(L C-I O-O c c)$ versus $C \mathrm{~s}\left(M_{i j}\right)$ are all statistically significant at $1 \%$ level, except for the sub-score $\mathrm{VS}^{\mathrm{IO}}$ of $C \mathrm{~s}(L C-I O-O c c)$ and $C \mathrm{~s}(I O)(84$ and 85$)$.

Table 7: Candidate Cluster Configurations $\boldsymbol{C}^{*} \mathbf{s}$ (Top-40 Rankings in both VS-Cluster and VS-Industry)

\begin{tabular}{|c|c|c|c|c|c|c|c|c|c|c|}
\hline \multirow[b]{3}{*}{$C^{*} \mathrm{~s}$} & \multirow{2}{*}{\multicolumn{3}{|c|}{ Model Choices }} & \multicolumn{6}{|c|}{ Validation Scores } & \multirow{3}{*}{$\begin{array}{c}\text { Overlap Score } \\
\text { OS }_{\text {C-Candidates }} \\
\text { Score } \\
\end{array}$} \\
\hline & & & & \multicolumn{2}{|c|}{ VS-Cluster } & \multicolumn{2}{|c|}{ VS-Industry } & \multicolumn{2}{|c|}{ VS } & \\
\hline & $\mathrm{M}_{\mathrm{ij}}$ & Numc & Function & Rank & Score & Rank & Score & Rank & Score & \\
\hline$C^{*}$ & LC-IO-Occ & 47 & Hiw & 14 & 81.6 & 4 & 73.7 & 1 & 77.7 & 77.6 \\
\hline $\mathrm{C}_{2}$ & LC-IO-Occ & 56 & Hiw & 12 & 81.7 & 8 & 73.3 & 2 & 77.5 & 75.5 \\
\hline $\mathrm{C}_{3}$ & LC-IO-Occ & 48 & Hiw & 9 & 81.8 & 10 & 73.3 & 3 & 77.5 & 77.7 \\
\hline $\mathrm{C}_{4}$ & LC-IO-Occ & 55 & Hiw & 15 & 81.6 & 9 & 73.3 & 4 & 77.5 & 75.9 \\
\hline $\mathrm{C}_{5}$ & LC-IO-Occ & 53 & Hiw & 7 & 82.1 & 17 & 72.8 & 5 & 77.4 & 76.8 \\
\hline $\mathrm{C}_{6}$ & LC-IO-Occ & 49 & Hiw & 8 & 81.9 & 12 & 72.9 & 6 & 77.4 & 77.6 \\
\hline $\mathrm{C}_{7}$ & LC-IO-Occ & 54 & Hiw & 11 & 81.7 & 11 & 73.0 & 7 & 77.4 & 76.4 \\
\hline $\mathrm{C}_{8}$ & LC-IO-Occ & 42 & Hiw & 39 & 81.0 & 6 & 73.7 & 8 & 77.3 & 77.0 \\
\hline $\mathrm{C}_{9}$ & LC-IO-Occ & 59 & Hiw & 17 & 81.6 & 13 & 72.8 & 11 & 77.2 & 73.6 \\
\hline $\mathrm{C}_{10}$ & LC-IO-Occ & 57 & Hiw & 16 & 81.6 & 16 & 72.8 & 12 & 77.2 & 74.9 \\
\hline $\mathrm{C}_{11}$ & LC-IO-Occ & 58 & Hiw & 21 & 81.5 & 14 & 72.8 & 14 & 77.1 & 74.3 \\
\hline $\mathrm{C}_{12}$ & LC-Est & 43 & Hiw & 13 & 81.7 & 23 & 72.5 & 15 & 77.1 & 39.5 \\
\hline $\mathrm{C}_{13}$ & $\mathrm{LC}$ & 41 & Hiw & 3 & 82.6 & 40 & 71.3 & 18 & 77.0 & 43.7 \\
\hline $\mathrm{C}_{14}$ & LC-IO-Occ & 50 & Hiw & 19 & 81.5 & 27 & 72.3 & 19 & 76.9 & 77.3 \\
\hline $\mathrm{C}_{15}$ & LC-IO-Occ & 60 & Hiw & 27 & 81.3 & 21 & 72.6 & 20 & 76.9 & 73.0 \\
\hline $\mathrm{C}_{16}$ & LC-IO-Occ & 52 & Hiw & 20 & 81.5 & 29 & 72.3 & 21 & 76.9 & 77.1 \\
\hline $\mathrm{C}_{17}$ & LC-IO-Occ & 51 & Hiw & 26 & 81.4 & 28 & 72.3 & 22 & 76.8 & 77.1 \\
\hline $\mathrm{C}_{18}$ & COI-IO-Occ & 44 & Hiw & 38 & 81.0 & 18 & 72.7 & 23 & 76.8 & 68.3 \\
\hline $\mathrm{C}_{19}$ & LC & 42 & Hiw & 6 & 82.1 & 31 & 71.4 & 24 & 76.8 & 43.4 \\
\hline $\mathrm{C}_{20}$ & COI-IO-Occ & 42 & Hiw & 39 & 81.0 & 19 & 72.6 & 25 & 76.8 & 67.7 \\
\hline $\mathrm{C}_{21}$ & LC-Est & 41 & Hiw & 36 & 81.1 & 26 & 72.3 & 26 & 76.7 & 39.9 \\
\hline $\mathrm{C}_{22}$ & $\mathrm{LC}$ & 44 & Hiw & 18 & 81.5 & 34 & 71.4 & 30 & 76.5 & 42.9 \\
\hline $\mathrm{C}_{23}$ & $\mathrm{LC}$ & 43 & Hiw & 25 & 81.4 & 32 & 71.4 & 31 & 76.4 & 43.0 \\
\hline $\mathrm{C}_{24}$ & IO-Occ & 44 & Hiw & 27 & 81.3 & 34 & 71.4 & 32 & 76.3 & 69.7 \\
\hline
\end{tabular}

Notes: Rank is across the $713 \mathrm{Cs}$. Overlap Score -Candidates $_{\text {is the }}$ average cluster overlap between the focal $C$ and the 23 other sets of definitions. Hiw refers to the Hierarchical-Ward's clustering function. 
Table 8: Overview of Proposed Set of Benchmark Cluster Definitions $C^{* *}$

\begin{tabular}{|c|c|c|c|c|c|c|c|c|}
\hline \multirow[t]{2}{*}{ Cluster Name } & \multirow{2}{*}{$\begin{array}{c}\text { No. } \\
\text { Industries }\end{array}$} & \multirow{2}{*}{$\begin{array}{c}\text { \% Traded } \\
\text { Employ }\end{array}$} & \multicolumn{2}{|c|}{ WCR } & \multicolumn{2}{|c|}{$W_{C R}{ }^{\text {LC-Emp }} W_{C} \mathbf{C R}^{\text {LC-Est }}$} & \multirow{2}{*}{$\begin{array}{c}\mathbf{W C R}^{\mathbf{I O}} \\
{[0,1]}\end{array}$} & \multirow{2}{*}{$\begin{array}{c}\mathbf{W C R}^{\text {Occ }} \\
{[-1,1]}\end{array}$} \\
\hline & & & Rank & Score & {$[-1,1]$} & {$[-1,1]$} & & \\
\hline Aerospace Vehicles and Defense & 7 & $1.3 \%$ & 1 & 1.93 & 0.20 & 0.63 & 0.15 & 0.87 \\
\hline Agricultural Inputs and Services & 9 & $0.2 \%$ & 1 & 1.14 & 0.35 & 0.53 & 0.10 & 0.46 \\
\hline Apparel & 21 & $0.4 \%$ & 1 & 2.28 & 0.45 & 0.74 & 0.11 & 1.00 \\
\hline Automotive & 26 & $1.9 \%$ & 1 & 2.27 & 0.31 & 0.62 & 0.22 & 0.65 \\
\hline Biopharmaceuticals & 4 & $0.6 \%$ & 1 & 3.35 & 0.59 & 0.76 & 0.23 & 1.00 \\
\hline Business Services & 33 & $24.2 \%$ & 1 & 1.17 & 0.66 & 0.83 & 0.04 & 0.25 \\
\hline Coal Mining & 4 & $0.2 \%$ & 2 & 2.30 & 0.44 & 0.53 & 0.22 & 0.62 \\
\hline Communications Equipment and Services & 8 & $1.3 \%$ & 1 & 2.37 & 0.47 & 0.79 & 0.23 & 0.41 \\
\hline Construction Products and Services & 20 & $1.8 \%$ & 1 & 1.81 & 0.39 & 0.61 & 0.21 & 0.29 \\
\hline Distribution and Electronic Commerce & 62 & $13.0 \%$ & 1 & 2.19 & 0.67 & 0.82 & 0.12 & 0.63 \\
\hline Downstream Chemical Products & 13 & $0.6 \%$ & 1 & 1.30 & 0.39 & 0.69 & 0.04 & 0.71 \\
\hline Downstream Metal Products & 16 & $1.0 \%$ & 1 & 1.05 & 0.28 & 0.58 & 0.02 & 0.82 \\
\hline Education and Knowledge Creation & 15 & $6.8 \%$ & 1 & 1.34 & 0.70 & 0.85 & 0.03 & 0.38 \\
\hline Electric Power Generation and Transmission & 5 & $0.3 \%$ & 2 & 0.90 & 0.30 & 0.31 & 0.00 & 1.00 \\
\hline Environmental Services & 7 & $0.2 \%$ & 1 & 2.81 & 0.57 & 0.78 & 0.22 & 0.67 \\
\hline Financial Services & 26 & $4.9 \%$ & 1 & 2.04 & 0.54 & 0.71 & 0.16 & 0.51 \\
\hline Fishing and Fishing Products & 5 & $0.1 \%$ & 1 & 3.40 & 0.48 & 0.63 & 0.28 & 1.00 \\
\hline Food Processing and Manufacturing & 47 & $2.2 \%$ & 1 & 0.82 & 0.26 & 0.46 & 0.03 & 0.72 \\
\hline Footwear & 6 & $0.0 \%$ & 1 & 5.22 & 0.09 & 0.31 & 0.72 & 0.75 \\
\hline Forestry & 4 & $0.2 \%$ & 1 & 3.47 & 0.59 & 0.66 & 0.36 & 0.51 \\
\hline Furniture & 12 & $0.9 \%$ & 1 & 1.43 & 0.34 & 0.76 & 0.03 & 0.83 \\
\hline Hospitality and Tourism & 31 & $7.0 \%$ & 5 & 0.45 & 0.50 & 0.60 & 0.01 & 0.21 \\
\hline Information Technology and Analytical Instrument & 27 & $2.6 \%$ & 1 & 1.32 & 0.43 & 0.78 & 0.03 & 0.69 \\
\hline Insurance Services & 8 & $3.8 \%$ & 1 & 4.35 & 0.59 & 0.82 & 0.39 & 0.91 \\
\hline Jewelry and Precious Metals & 4 & $0.1 \%$ & 1 & 5.49 & 0.53 & 0.79 & 0.55 & 1.00 \\
\hline Leather and Related Products & 6 & $0.1 \%$ & 2 & 1.32 & 0.35 & 0.75 & 0.01 & 0.86 \\
\hline Lighting and Electrical Equipment & 15 & $0.8 \%$ & 1 & 1.49 & 0.36 & 0.75 & 0.02 & 0.94 \\
\hline Livestock Processing & 5 & $1.2 \%$ & 1 & 1.66 & 0.34 & 0.56 & 0.14 & 0.65 \\
\hline Marketing, Design, and Publishing & 22 & $2.9 \%$ & 1 & 1.68 & 0.76 & 0.90 & 0.04 & 0.48 \\
\hline Medical Devices & 5 & $0.7 \%$ & 1 & 2.12 & 0.52 & 0.89 & 0.07 & 0.87 \\
\hline Metal Mining & 8 & $0.1 \%$ & 1 & 0.60 & 0.09 & 0.23 & 0.05 & 0.81 \\
\hline Metalworking Technology & 17 & $1.2 \%$ & 1 & 1.43 & 0.62 & 0.82 & 0.02 & 0.59 \\
\hline Music and Sound Recording & 5 & $0.1 \%$ & 1 & 6.19 & 0.85 & 0.94 & 0.57 & 1.00 \\
\hline Nonmetal Mining & 13 & $0.2 \%$ & 1 & 0.63 & 0.13 & 0.19 & 0.03 & 0.89 \\
\hline Oil and Gas Production and Transportation & 12 & $1.3 \%$ & 1 & 1.47 & 0.61 & 0.64 & 0.10 & 0.36 \\
\hline Paper and Packaging & 20 & $0.9 \%$ & 1 & 1.62 & 0.28 & 0.52 & 0.08 & 0.97 \\
\hline Performing Arts & 8 & $0.7 \%$ & 1 & 1.84 & 0.65 & 0.86 & 0.10 & 0.42 \\
\hline Plastics & 15 & $1.6 \%$ & 1 & 2.04 & 0.49 & 0.76 & 0.10 & 0.82 \\
\hline Printing Services & 13 & $1.3 \%$ & 1 & 2.54 & 0.54 & 0.87 & 0.15 & 0.78 \\
\hline Production Technology and Heavy Machinery & 41 & $2.3 \%$ & $\mathbf{1}$ & 1.08 & 0.29 & 0.59 & 0.01 & 0.89 \\
\hline Recreational and Small Electric Goods & 15 & $0.5 \%$ & 1 & 1.30 & 0.32 & 0.74 & 0.01 & 0.90 \\
\hline Textile Manufacturing & 23 & $0.5 \%$ & 1 & 1.20 & 0.35 & 0.52 & 0.10 & 0.49 \\
\hline Tobacco & 3 & $0.0 \%$ & 1 & $\mathbf{7 . 5 3}$ & 0.09 & 0.35 & 1.00 & 1.00 \\
\hline Trailers, Motor Homes, and Appliances & 9 & $0.3 \%$ & $\mathbf{1}$ & 0.52 & 0.08 & 0.26 & 0.01 & 0.90 \\
\hline Transportation and Logistics & 17 & $3.8 \%$ & 1 & 1.14 & 0.42 & 0.76 & 0.10 & 0.22 \\
\hline Upstream Chemical Products & 12 & $0.4 \%$ & 1 & 1.24 & 0.12 & 0.32 & 0.09 & 0.95 \\
\hline Upstream Metal Manufacturing & 26 & $0.9 \%$ & 1 & 0.97 & 0.25 & 0.50 & 0.04 & 0.76 \\
\hline Video Production and Distribution & 6 & $0.5 \%$ & $\mathbf{1}$ & 3.13 & 0.69 & 0.83 & 0.23 & 0.69 \\
\hline Vulcanized and Fired Materials & 17 & $0.6 \%$ & 1 & 0.94 & 0.26 & 0.53 & 0.02 & 0.78 \\
\hline Water Transportation & 12 & $0.7 \%$ & $\mathbf{1}$ & 1.73 & 0.37 & 0.69 & 0.16 & 0.45 \\
\hline Wood Products & 13 & $0.9 \%$ & 1 & 1.71 & 0.36 & 0.54 & 0.10 & 0.87 \\
\hline Average & & & & 2.07 & 0.42 & 0.65 & 0.15 & 0.71 \\
\hline
\end{tabular}

Notes: WCR is the average of the (standardized) $\mathrm{WCR}^{\mathrm{LC}-\mathrm{Emp}}, \mathrm{WCR}^{\mathrm{LC}-\mathrm{Est}}, \mathrm{WCR}^{\mathrm{IO}}$, and $\mathrm{WCR}^{\text {Occ }}$. 
Table 9.1: Aerospace Vehicles and Defense Cluster

Description: Establishments in this cluster manufacture aircraft, space vehicles, guided missiles, and related parts. It also contains firms that manufacture the necessary search and navigation equipment used by these products.

\begin{tabular}{|lllcc|}
\hline NAICS & NAICS Name & Subcluster Name & \multicolumn{2}{c|}{$\begin{array}{c}\text { Within Cluster Relatedness (WCR } \\
\text { Rank (1=best) }\end{array}$} \\
\hline 336411 & Aircraft Mfg & Aircraft & 1 & 3.53 \\
336412 & Aircraft Engine \& Engine Parts Mfg & Aircraft & 1 & 1.65 \\
336413 & Other Aircraft Parts \& Auxiliary Equipment Mfg & Aircraft & 1 & 2.22 \\
336414 & Guided Missile \& Space Vehicle Mfg & Missiles \& Space Vehicles & 1 & 1.47 \\
336415 & Guided Missile \& Space Vehicle Propulsion Unit \& & Missiles \& Space Vehicles & 1 & 1.89 \\
& Propulsion Unit Parts Mfg & Missiles \& Space Vehicles & 1 & 0.99 \\
336419 & Other Guided Missile \& Space Vehicle Parts \& & Auxiliary Equipment Mfg & 1 & 1.77 \\
334511 & Search, Detection, Navigation, Guidance, & Search \& Navigation Equipment & 1 \\
& Aeronautical, \& Nautical System \& Instrument Mfg & & & 1 \\
\hline
\end{tabular}

\section{Table 9.2: Oil and Gas Production and Transportation Cluster}

Description: This cluster includes firms involved in locating, extracting, refining, \& transporting oil \& gas. This includes companies that manufacture the equipment necessary to extract oil \& gas, as well as companies that provide support services for oil \& gas operations \& pipeline transport.

\begin{tabular}{|lllcc|}
\hline NAICS & NAICS Name & Subcluster Name & \multicolumn{2}{c|}{ Within Cluster Relatedness (WCR } \\
& & & 1 & Rank (1=best) \\
\hline 324110 & Petroleum Refineries & Petroleum Processing & 2.58 \\
324199 & All Other Petroleum \& Coal Products Mfg & Petroleum Processing & 1 & 0.83 \\
213112 & Support Activities for Oil \& Gas Operations & Support Activities for Oil \& Gas Operations & 1 & 2.17 \\
541360 & Geophysical Surveying \& Mapping Services & Support Activities for Oil \& Gas Operations & 1 & 0.79 \\
213111 & Drilling Oil \& Gas Wells & Drilling Wells & 1 & 0.94 \\
211111 & Crude Petroleum \& Natural Gas Extraction & Oil \& Gas Extraction & 1 & 2.47 \\
211112 & Natural Gas Liquid Extraction & Oil \& Gas Extraction & 1 & 2.17 \\
333132 & Oil \& Gas Field Machinery \& Equipment Mfg & Oil \& Gas Machinery & 1 & 1.15 \\
486110 & Pipeline Transportation of Crude Oil & Pipeline Transportation & 1 & 1.29 \\
486210 & Pipeline Transportation of Natural Gas & Pipeline Transportation & 1 & 1.10 \\
486910 & Pipeline Transportation of Refined Petroleum Products & Pipeline Transportation & 2 & 1.11 \\
486990 & All Other Pipeline Transportation & Pipeline Transportation & 1 & 1.09 \\
\hline
\end{tabular}

\section{Table 9.3: Insurance Services Cluster}

Description: This cluster consists of firms providing a range of insurance types, as well as support services such as reinsurance and claims adjustment.

\begin{tabular}{|c|c|c|c|c|}
\hline \multirow[t]{2}{*}{ NAICS } & \multirow[t]{2}{*}{ NAICS Name } & \multirow[t]{2}{*}{ Subcluster Name } & \multicolumn{2}{|c|}{ Within Cluster Relatedness $\left(\mathbf{W C R}_{\text {ic }}\right)$} \\
\hline & & & Rank ( $1=$ best $)$ & Score \\
\hline 524291 & Claims Adjusting & Insurance Related Services & 1 & 6.17 \\
\hline 524298 & All Other Insurance Related Activities & Insurance Related Services & 1 & 6.20 \\
\hline 524113 & Direct Life Insurance Carriers & Insurance Carriers & 1 & 3.93 \\
\hline 524114 & Direct Health \& Medical Insurance Carriers & Insurance Carriers & 1 & 3.92 \\
\hline 524126 & Direct Property \& Casualty Insurance Carriers & Insurance Carriers & 1 & 3.92 \\
\hline 524127 & Direct Title Insurance Carriers & Insurance Carriers & 1 & 3.55 \\
\hline 524128 & Other Direct Insurance Carriers & Insurance Carriers & 1 & 3.32 \\
\hline 524130 & Reinsurance Carriers & Reinsurance Carriers & 1 & 3.76 \\
\hline
\end{tabular}

\section{Table 9.4: Medical Devices Cluster}

Description: Establishments in this cluster primarily manufacture surgical, dental, \& optical instruments \& supplies.

\begin{tabular}{|lllcc|}
\hline NAICS & NAICS Name & Subcluster Name & \multicolumn{2}{c|}{ Within Cluster Relatedness (WCR } \\
& & & Rank (1=best) & Score \\
\hline $333314^{*}$ & Optical Instrument \& Lens Mfg & Optical Instruments \& Ophthalmic Goods & 1 & 1.98 \\
339115 & Ophthalmic Goods Mfg & Optical Instruments \& Ophthalmic Goods & 1 & 2.48 \\
339112 & Surgical \& Medical Instrument Mfg & Surgical \& Dental Instruments \& Supplies & 1 & 2.19 \\
339113 & Surgical Appliance \& Supplies Mfg & Surgical \& Dental Instruments \& Supplies & 1 & 2.34 \\
339114 & Dental Equipment \& Supplies Mfg & Surgical \& Dental Instruments \& Supplies & 1 & 1.61 \\
\hline
\end{tabular}

Note: "Marginal industry outliers reallocated from other cluster (see online Technical Appendix). 


\section{Table 9.5: Lighting and Electrical Equipment Cluster}

Description: This cluster contains firms involved in the manufacture of electrical equipment \& electronic components. The companies in this cluster manufacture wire for communications, wiring devices, fiber-optic cables, switchboards, lighting fixtures, motors, transformers, \& related products.

\begin{tabular}{|lllcc|}
\hline NAICS & NAICS Name & Subcluster Name & \multicolumn{2}{c|}{ Within Cluster Relatedness (WCR } \\
& & & 1 & Rank (1=best) \\
Score & 1.34 \\
335110 & Electric Lamp Bulb \& Part Mfg & Lighting Fixtures \& Parts & 1 & 1.77 \\
335121 & Residential Electric Lighting Fixture Mfg & Lighting Fixtures \& Parts & 1 & 1.77 \\
335122 & Commercial, Industrial, \& Institutional Electric & Lighting Fixtures \& Parts & 1 & 1.68 \\
& Lighting Fixture Mfg & Lighting Fixtures \& Parts & 1 & 1.62 \\
335129 & Other Lighting Equipment Mfg & Electrical Equipment & 1 & 1.30 \\
335311 & Power, Distribution, \& Specialty Transformer Mfg & Electrical Equipment & 1 & 1.48 \\
335312 & Motor \& Generator Mfg & Electrical Equipment & 1 & 1.64 \\
335313 & Switchgear \& Switchboard Apparatus Mfg & Electrical Equipment & 1 & 1.39 \\
335314 & Relay \& Industrial Control Mfg & Electrical Components & 1 & 1.61 \\
335921 & Fiber Optic Cable Mfg & Electrical Components & 1 & 1.67 \\
335929 & Other Communication \& Energy Wire Mfg & Electrical Components & 1 & 1.23 \\
335931 & Current-Carrying Wiring Device Mfg & Electrical Components & 1 & 1.15 \\
335932 & Noncurrent-Carrying Wiring Device Mfg & Electrical Components & 1 & 1.65 \\
335991 & Carbon \& Graphite Product Mfg & Electrical Components & 1 & 1.00 \\
$335999^{*}$ All Other Miscellaneous Electrical Equipment \& & Component Mfg & Storage Batteries & 1 \\
335911 & Storage Battery Mfg & Other clusters (see Online Technical Appendix). & \\
\hline
\end{tabular}

Note: *Marginal industry outliers reallocated from other clusters (see online Technical Appendix).

\section{Table 9.6: Recreational and Small Electric Goods Cluster}

Description: This cluster contains establishments that manufacture end-use products for recreational \& decorative purposes. These products include games, toys, bicycles, motorcycles, musical instruments, sporting goods, art supplies, office supplies, shades, \& home accessories. This cluster also incorporates firms that produce small, simple electric goods like hairdryers, fans, \& office machinery.

\begin{tabular}{|lllcc|}
\hline NAICS & NAICS Name & Subcluster Name & \multicolumn{2}{c|}{ Within Cluster Relatedness (WCR $_{\text {Rank (1=best) }}$} \\
& & & 3 & Score \\
3337920 & Blind \& Shade Mfg & Recreational \& Decorative Goods & 3 & 1.37 \\
339992 & Musical Instrument Mfg & Recreational \& Decorative Goods & 3 & 1.60 \\
339993 & Fastener, Button, Needle, \& Pin Mfg & Recreational \& Decorative Goods & 1 & 1.37 \\
339999 & All Other Miscellaneous Mfg & Recreational \& Decorative Goods & 2 & 1.58 \\
339931 & Doll \& Stuffed Toy Mfg & Games, Toys, \& Children's Vehicles & 1 & 1.17 \\
339932 & Game, Toy, \& Children's Vehicle Mfg & Games, Toys, \& Children's Vehicles & 1 & 1.44 \\
$336991^{*}$ Motorcycle, Bicycle, \& Parts Mfg & Motorcycles \& Bicycles & 3 & 0.94 \\
339920 & Sporting \& Athletic Goods Mfg & Sporting \& Athletic Goods & 4 & 1.25 \\
333313 & Office Machinery Mfg & Office Supplies & 3 & 1.00 \\
$333315^{*}$ Photographic \& Photocopying Equipment Mfg & Office Supplies & 2 & 1.35 \\
339941 & Pen \& Mechanical Pencil Mfg & Office Supplies & 1 & 1.43 \\
339942 & Lead Pencil \& Art Good Mfg & Office Supplies & 1 & 1.50 \\
339943 & Marking Device Mfg & Office Supplies & 1 & 1.61 \\
339944 & Carbon Paper \& Inked Ribbon Mfg & Office Supplies & 1 & 1.11 \\
$335211^{*}$ Electric Housewares \& Household Fan Mfg & Electric Housewares & 0.78 \\
\hline
\end{tabular}

Note: ${ }^{*}$ Marginal industry outliers reallocated from other clusters (see online Technical Appendix). 
Table 10: Validation Scores (sub-scores) for Selected Sets of Cluster Definitions

\begin{tabular}{|c|c|c|c|c|c|c|c|c|c|c|c|c|}
\hline & \multicolumn{3}{|c|}{\begin{tabular}{|c|} 
BCD $\left(\boldsymbol{C}^{* * *}\right)$ \\
51 clusters, 778 industries
\end{tabular}} & \multicolumn{3}{|c|}{\begin{tabular}{|c|} 
3-digit NAICS \\
66 clusters, 778 industries
\end{tabular}} & \multicolumn{3}{|c|}{\begin{tabular}{|c|} 
Porter $(\mathbf{2 0 0 3})$ \\
41 clusters, 685 industries
\end{tabular}} & \multicolumn{3}{|c|}{$\begin{array}{c}\text { Feser (2005) } \\
44 \text { clusters, } 910 \text { industries }\end{array}$} \\
\hline & \multicolumn{3}{|c|}{ Cluster Industry } & \multicolumn{3}{|c|}{ Cluster Industry } & \multicolumn{3}{|c|}{ Cluster Industry } & \multicolumn{3}{|c|}{ Cluster Industry } \\
\hline VS Scores & 82 & 73 & 78 & 56 & 59 & 58 & 77 & 69 & 73 & 70 & 67 & 69 \\
\hline VS Rank & 9 & 7 & 2 & 717 & 710 & 717 & 261 & 146 & 200 & 541 & 258 & 429 \\
\hline VS Sub-scores & & & & & & & & & & & & \\
\hline $\mathrm{VS}^{\mathrm{LC}-\mathrm{Emp}}$ & 70 & 63 & 66 & 49 & 46 & 47 & 68 & 66 & 67 & 48 & 59 & 53 \\
\hline $\mathrm{VS}^{\mathrm{LC}-\mathrm{Est}}$ & 73 & 64 & 68 & 51 & 49 & 50 & 67 & 63 & 65 & 61 & 58 & 59 \\
\hline $\mathrm{VS}^{\mathrm{IO}}$ & 87 & 74 & 81 & 39 & 44 & 42 & 77 & 68 & 73 & 72 & 61 & 67 \\
\hline $\mathrm{VS}^{\mathrm{Occ}}$ & 98 & 93 & 95 & 88 & 97 & 92 & 94 & 80 & 87 & 99 & 92 & 95 \\
\hline
\end{tabular}

Notes: ${ }^{*}$ VS is the average of VS-Cluster and VS-Industry. The VS rankings are computed across the $713 \mathrm{Cs}$ and the 4 sets included in the table ( $1=$ best, $717=$ worst). Each set of clusters contains mutually exclusive groups.

Table 11: Overlap between $C^{* * *}$ and Other Sets of Cluster Definitions

\begin{tabular}{lccc}
\hline Overlap Score & $\boldsymbol{C}^{* * *}$ and 3-digit NAICS & $\boldsymbol{C}^{* *}$ and Porter (2003) & $\boldsymbol{C}^{* * *}$ and Feser (2005) \\
\hline$C^{* *} \rightarrow C$ & $66 \%$ & $55 \%$ & $54 \%$ \\
$C^{* *} \leftarrow C$ & $56 \%$ & $58 \%$ & $54 \%$ \\
$C^{* *} \leftrightarrow C$ (Average) & $61 \%$ & $57 \%$ & $54 \%$ \\
\hline Industries in $C^{* *}$ and $C$ & 778 & 671 & 734 \\
No. clusters in $C^{* *}, C$ & 51,66 & 47,41 & 49,44 \\
\hline
\end{tabular}

Note: We compute the overlap score for the sub-set of industries in common with $C^{* *}$.

Figure 1: Top Regional Aerospace Vehicles and Defense Clusters in 2010 (Economic Areas; $C^{* *}$ )

EAs with Top Employment Specialization and Share of U.S. Cluster

EAs with Top Employment Specialization

EAs with Top Employment Share

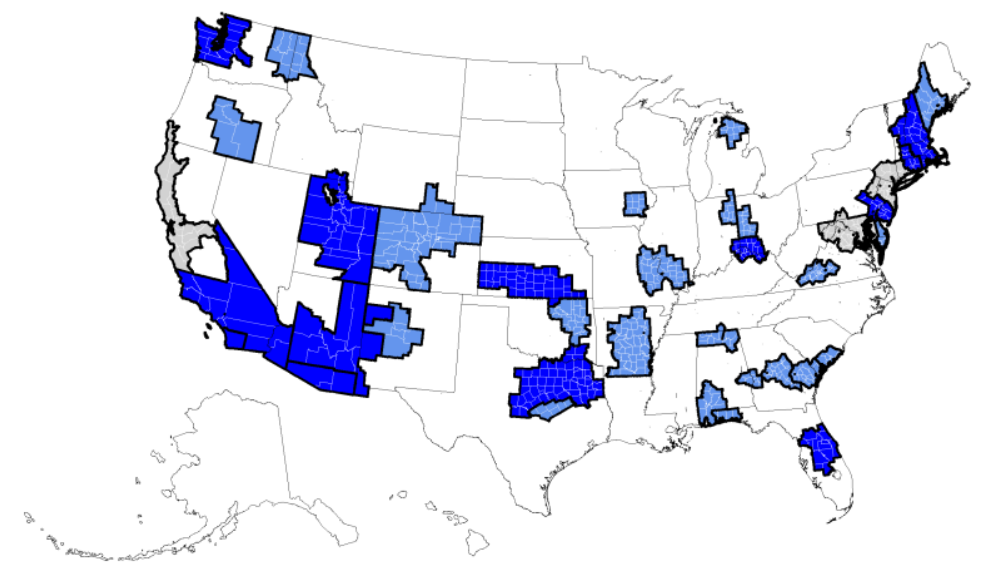

Notes: Economic Areas (EAs) with Top Employment Specialization in a cluster meet these criteria: Location Quotient (LQ) of Cluster Employment must be greater than 75th percentile when measured across all EAs with non-zero employment in the cluster. Secondary criteria to differentiate marginal cases: LQ of Cluster Employment greater than 1.0, Share of National Cluster Employment greater than 25th percentile, Share of National Cluster Establishments greater than 25th percentile. EAs with Top Employment Share in a cluster meet this criterion: Share of National Cluster Employment must be greater than 90th percentile when measured across all EAs with non-zero employment in the cluster. EAs with Top Employment Specialization and Share meet all of the above criteria. 


\section{Appendix A}

Table A1: Similarity Matrices Used to Generate Sets of Cluster Definitions Cs

\begin{tabular}{lcll}
\hline \multicolumn{1}{c}{ Similarity Matrix } & No. of $\boldsymbol{C} \mathbf{s}$ & \multicolumn{1}{c}{ Type of $\mathbf{M}_{\mathbf{i j}}$} & \multicolumn{1}{c}{ Definition } \\
\hline LC-Emp & 155 & Unidimensional & Locational Correlation of employment [-1, 1] \\
LC-Est & 155 & Unidimensional & Locational Correlation of establishments [-1, 1] \\
IO & 31 & Unidimensional & Input-Output link [0, 1] \\
Occ & 93 & Unidimensional & Labor Occupation link [-1, 1] \\
COI & 31 & Unidimensional & Coagglomeration Index \\
\hline LC-IO-Occ & 31 & Multidimensional & Average of (standardized) LC-Emp, LC-Est, IO, Occ \\
COI-IO-Occ & 31 & Multidimensional & Average of (standardized) COI, IO, Occ \\
LC & 31 & Multidimensional & Average of LC-Emp, LC-Est \\
IO-Occ & 31 & Multidimensional & Average of (standardized) IO, Occ \\
LC-Emp-IO & 31 & Multidimensional & Average of (standardized) LC-Emp, IO \\
LC-Est-IO & 31 & Multidimensional & Average of (standardized) LC-Est, IO \\
LC-Emp-Occ & 31 & Multidimensional & Average of LC-Emp, Occ \\
LC-Est-Occ & 31 & Multidimensional & Average of LC-Est, Occ \\
\hline
\end{tabular}

An online Technical Appendix, with a detailed cluster-by-cluster overview of the proposed set of benchmark cluster definitions $\left(C^{* *}\right)$, may be accessed here. 